\title{
Adenoviral vector carrying glial cell-derived neurotrophic factor for direct gene therapy in comparison with human umbilical cord blood cell-mediated therapy of spinal cord injury in rat
}

\author{
YO Mukhamedshina ${ }^{1}$, GF Shaymardanova ${ }^{2}$, EE Garanina ${ }^{1}$, II Salafutdinov ${ }^{1}$, AA Rizvanov ${ }^{1}$, \\ RR Islamov ${ }^{3}$ and YA Chelyshev ${ }^{3}$
}

Study design: Experimental study.

Objective: To evaluate the treatment of spinal cord injury with glial cell-derived neurotrophic factor (GDNF) delivered using an adenoviral vector (AdV-GDNF group) in comparison with treatment performed using human umbilical cord blood mononuclear cells (UCB-MCs)-transduced with an adenoviral vector carrying the GDNF gene (UCB-MCs+AdV-GDNF group) in rat.

Setting: Kazan, Russian Federation.

Methods: We examined the efficacy of AdV-GDNF and UCB-MCs+AdV-GDNF therapy by conducting behavioral tests on the animals and morphometric studies on the spinal cord, performing immunofluorescence analyses on glial cells, investigating the survival and migration potential of UCB-MCs, and evaluating the expression of the recombinant GDNF gene.

Results: At the 30th postoperative day, equal positive locomotor recovery was observed after both direct and cell-based GDNF therapy. However, after UCB-MCs-mediated GDNF therapy, the area of preserved tissue and the number of spared myelinated fibers were higher than those measured after direct GDNF gene therapy. Moreover, we observed distinct changes in the populations of glial cells; expression patterns of the specific markers for astrocytes (GFAP, S100B and AQP4), oligodendrocytes (PDGFoR and Cx47) and Schwann cells (PO) differed in various areas of the spinal cord of rats treated with AdV-GDNF and UCB-MCs+AdV-GDNF.

Conclusion: The differences detected in the AdV-GDNF and UCB-MCs+AdV-GDNF groups could be partially explained by the action of UCB-MCs. We discuss the insufficiency and the advantages of these two methods of GDNF gene delivery into the spinal cord after traumatic injury.

Spinal Cord (2016) 54, 347-359; doi:10.1038/sc.2015.161; published online 29 September 2015

\section{INTRODUCTION}

Spinal cord injury (SCI) leads to complex pathological changes that include the death of neurons and glial cells and the demyelination and degeneration of nerve fibers. The limited growth capacity of mature central nervous system (CNS) neurons and the non-permissive environment of the CNS for axon regrowth are the main factors responsible for the little or no regeneration toward targets displayed by injured axons and for the permanent functional deficit observed after SCI. One promising approach for preventing neurodegeneration involves locally treating the site of injury in order to increase the expression of neurotrophic factors. Exploiting the stimulatory effects of neurotrophic factors on neuroregeneration appears to also be useful for SCI treatment, and one neurotrophic factor that is particularly suitable for SCI treatment is glial cell-derived neurotrophic factor (GDNF). GDNF is a member of the TGF- $\beta$ superfamily that binds to the receptor GFR $\alpha 1$ and upregulates several signaling pathways; these pathways include those involving intracellular RAS/extracellular signalregulated kinase, phosphatidylinositol 3-kinase/AKT, p38 mitogen- activated protein kinase, c-Jun N-terminal kinase ${ }^{1}$ and Src family kinases, ${ }^{2,3}$ which promote neuronal survival and axon regrowth ${ }^{4-7}$ by, for instance, increasing the expression of regeneration-associated genes such as $\beta$ III-tubulin and GAP-43 in chronically injured rubrospinal tract neurons. ${ }^{8}$

In a previous study, nonviral GDNF gene delivery through a receptor-mediated mechanism rescued motor neurons after axotomy, and the gene was demonstrated to be expressed in motor neurons for up to 8 weeks. ${ }^{6}$ However, compared with nonviral delivery, cell-based gene delivery or direct gene therapy is more often used for stimulating neuroregeneration. These approaches can be used for increasing the expression of neurotrophic factors and anti-apoptotic, cell adhesion and other biologically active molecules at injury sites.

Previous studies on direct GDNF gene therapy for SCI indicated that the treatment resulted in the preservation of nervous tissue and functional recovery. Liposome-mediated GDNF gene transfer, performed using a recombinant plasmid pEGFP (enhanced green fluorescent protein)-GDNF cDNA complex, produced protective

${ }^{1}$ OpenLab Gene and Cell Technologies, Kazan (Volga Region) Federal University, Kazan, Russia; ${ }^{2}$ Kazan Institute of Biochemistry and Biophysics, Russian Academy of Sciences, Kazan, Russia and ${ }^{3}$ Department of Hystology, Kazan State Medical University, Kazan, Russia

Correspondence: Dr YO Mukhamedshina, OpenLab Gene and Cell Technologies, Kazan (Volga Region) Federal University, Kremlevskaya St 18, Kazan 420008, Tatarstan, Russia. E-mail: yana.k-z-n@mail.ru

Received 29 April 2015; revised 10 July 2015; accepted 12 August 2015; published online 29 September 2015 
effects on motor neurons and promoted corticospinal tract regeneration and motor function improvement following SCI. ${ }^{9}$ Adenovirusmediated GDNF gene delivery reduced motor neuron injury after transient spinal cord ischemia. ${ }^{10}$ Intraspinal injection of a nonreplicating herpes simplex virus-based vector encoding GDNF, administered $2 \mathrm{~h}$ after blunt trauma to the thoracolumbar spinal cord, produced sustained improvement in motor behavioral outcomes for up to 5 weeks following injury. ${ }^{11}$ Lastly, following SCI, local administration of an adenoviral vector encoding GDNF rescued cortical motor neuron atrophy, preserved neuronal fibers and improved locomotion in rats. ${ }^{12,13}$

Cell-based GDNF gene delivery has been shown to promote the growth of motor axons and dorsal column sensory axons after partial and complete spinal cord transections and to induce remyelination. ${ }^{14}$ Moreover, olfactory ensheating cells transduced with a lentiviral vector encoding GDNF exerted a stronger effect on motor function recovery after spinal cord transection than did non-transduced olfactory ensheating cells. ${ }^{15}$ To date, numerous types of cells have been used in cell-based gene-delivery systems, including neural stem cells, neural progenitor cells, mesenchymal stem cells and umbilical cord blood mononuclear cells (UCB-MCs). UCB-MCs have been used for gene delivery because of their suitability for allogeneic and autologous transplantation, low immunogenicity, accessibility and ease of production and storage, and because of the lack of legal, ethical and religious concerns related to using these cells. ${ }^{16-18}$ In previous studies on amyotrophic lateral sclerosis treatment, we developed UCB-MCs transfected with a pBudCE4.1 dual-expression-cassette plasmid vector encoding vascular endothelial growth factor and cell adhesion molecule (VEGF-L1CAM) and VEGF-FGF2 $2^{19,20}$ and UCB-MCs transduced concurrently with adenoviral vectors encoding VEGF and GDNF, VEGF and neural cell adhesion molecule (NCAM), or GDNF and NCAM. ${ }^{21}$ The main positive action of the UCB-MCs was that they facilitated targeted delivery of the recombinant therapeutic molecules to motor neurons and thereby prolonged the survival of the neurons.

In this study, for use in SCI treatment, we evaluated direct GDNF gene therapy performed using an adenoviral vector in comparison with treatment involving the use of UCB-MCs transduced with an adenoviral vector coding GDNF. We used a rat SCI model and examined the efficacy of the two methods by conducting the BBB (Basso, Beattie and Bresnahan) behavioral test on the animals and morphometric studies on their spinal cord, performing immunofluorescence analyses on glial cells, and analyzing the expression of the recombinant GDNF gene.

\section{MATERIALS AND METHODS}

\section{Adenoviral vector generation}

Cloning of the gdnf gene cDNA into the plasmid vector PENTR-D/TOPO. The cDNA fragments of $g d n f$ were amplified in a C1000 Thermo Cycler (Bio-Rad, Hercules, CA, USA) by using Phusion High-fidelity DNA Polymerase (FINNZYMES) and the forward primer hGDNF-TOPO-F caccATGAAGTTATGGGA TGTCGTG and reverse primer hGDNF-Stop-SalI gtcgacTCAGATACATCCA CACCTTTTAGC (uppercase letters denote the coding sequence). Purified products were cloned (using topoisomerase) into the plasmid vector pENTR-D/ TOPO (Invitrogen, Carlsbad, CA, USA), and this was followed by transformation into Escherichia coli (E. coli) Top 10 competent cells. Colony PCR was performed using gene-specific primers, and the generation of the recombinant plasmids was confirmed through sequencing and restriction analysis.

Creation of adenoviral expression constructions by using gateway-cloning technology. To create adenoviral expression constructs, we performed LR-recombination from the donor plasmid pENTR-GDNF into the destination vector pAd/CMV/V5-Dest (Invitrogen). After transformation of E. coli competent cells, PCR screening was performed on the colonies and then sequencing was used for confirming that the insert of interest was present in the recombinant plasmids. Plasmid DNA was isolated by using a QIAFilter Plasmid Midiprep Kit (QIAGEN, Venlo, Netherlands) according to manufacturer recommendations.

Genetic modification (transfection) of HEK293A cells with the recombinant plasmid pAd-GDNF. HEK293 cells (Invitrogen) were cultured at $37^{\circ} \mathrm{C}$ in a humidified, $5 \% \mathrm{CO}_{2}$ atmosphere in Dulbecco's modified Eagle's medium supplemented with $10 \%$ fetal bovine serum, $1 \%$ antibiotic mixture of penicillin and streptomycin (Sigma, St Louis, MO, USA), and $2 \mathrm{~mm}$ L-glutamine. The cultured HEK293 cells were transfected with the obtained genetic constructs (pAd-GDNF) by using the transfection reagent TurboFect (Fermentas, Burlington, ON, Canada) according to manufacturer's recommendations. Protein expression was analyzed at $48 \mathrm{~h}$ after transfection by means of immunofluorescence (IF) analysis performed using rabbit polyclonal antibodies (Abs) against GDNF (Santa Cruz, Dallas, TX, USA, sc-328) and Alexa Fluor 488-conjugated donkey anti-rabbit IgG secondary Abs.

Production of recombinant adenoviruses. To produce the recombinant adenovirus Ad5-GDNF, an adenoviral vector plasmid was linearized using the restriction enzyme PacI. The purified linear plasmid was used for genetic modification of HEK293A cells by using the transfection reagent TurboFect. After transfection, we replaced the media every 2-3 days with fresh media until cytopathic changes appeared in cell morphology. On the 10th day after transfection, cell suspensions were collected in sterile $2 \mathrm{ml}$ tubes, and these were subjected to several freeze/thaw cycles and then centrifuged to prepare a crude viral lysate. The viral stock was stored at $-80^{\circ} \mathrm{C}$.

Amplification and titration of viruses. To obtain preparative amounts of the adenovirus carrying $g d n f$, HEK293A cells were infected with the crude viral lysate. After $72 \mathrm{~h}$, cell lysates were collected in $15 \mathrm{ml}$ tubes and subjected to several freeze/thaw cycles and then centrifuged to prepare a viral stock. The supernatant was filtered and further purified using two rounds of cesium chloride isopycnic gradient centrifugation, dialyzed against $50 \mathrm{~mm}$ Tris- $\mathrm{HCl}, \mathrm{pH}$ $7.5,150 \mathrm{~mm} \mathrm{NaCl}$, and then titered according to manufacturer's recommendations for the $\mathrm{pAd} / \mathrm{CMV} / \mathrm{V} 5-$ Dest system (Invitrogen).

\section{Isolation and identification of adenovirus-transduced UCB-MCs}

Umbilical cord blood was obtained from healthy women at a gestational stage of 39-40 weeks. Blood was sampled in accordance with the accepted protocols of legitimate and ethical standards at the stem cell bank of the Kazan State Medical University. Mononuclear blood cells were isolated as discussed previously. ${ }^{19}$ After purification, UCB-MCs were cultivated in RPMI-1640 medium supplemented with $10 \%$ fetal bovine serum and a mixture of $100 \mathrm{U} \mathrm{ml}^{-1}$ penicillin and $100 \mu \mathrm{g} \mathrm{ml}^{-1}$ streptomycin. UCB-MCs were seeded in $10 \mathrm{~cm}$ culture dishes and transduced with the recombinant adenoviruses Ad5-GDNF and Ad5-EGFP at a multiplicity of infection (MOI) of 10. Cells were incubated for $12-16 \mathrm{~h}$ in a humidified $5 \% \mathrm{CO}_{2}$ atmosphere at $37^{\circ} \mathrm{C}$, and then washed with Dulbecco's Phosphate Buffered Saline solution and injected into the experimental groups of animals at a density of $1 \times 10^{6}$ cells per $5 \mu$ l.

\section{Animals}

All experimental procedures were performed in accordance with the Kazan State Medical University Animal Care and Use Committee guidelines, and experimental protocols were consistent with the recommendations of the Physiological Section of the Russian National Committee on Bioethics. Rats were housed in clear plastic cages $(12 \mathrm{~h} / 12 \mathrm{~h}$ light/dark cycle) with food and water available ad-libitum. In this study, we used adult male and female Wistar rats (Pushchino Laboratory, Pushchino, Russia) and assigned the animals randomly into the experimental and control groups (Table 1).

\section{SCI and post-surgical care}

Rats were deeply anesthetized by intraperitoneally injecting them with chloral hydrate $\left(80 \mathrm{mg} \mathrm{ml}^{-1}, 0.4 \mathrm{ml}\right.$ per $100 \mathrm{~g}$; Sigma). Laminectomy was performed at vertebral level Th8. The impact rod (weight $10 \mathrm{~g}$, diameter $2 \mathrm{~mm}$ ) of the 
Table 1 Experimental groups

\begin{tabular}{|c|c|c|c|}
\hline Groups of animals & $\begin{array}{c}\text { Duration of } \\
\text { experiment, } \\
\text { days }\end{array}$ & Methods & $\begin{array}{c}\text { Number of } \\
\text { animals }\end{array}$ \\
\hline \multirow[t]{2}{*}{ Intact control } & 30 & Immunohistochemistry & 4 \\
\hline & 7 & Western blot & 2 \\
\hline $\mathrm{SCl}$ UCBCs & 30 & Immunohistochemistry, BBB & 12 \\
\hline \multicolumn{4}{|l|}{$+A d V-G D N F$} \\
\hline $\mathrm{SCl}$ UCBCs+AdV-EGFP & 30 & Immunohistochemistry, BBB & 11 \\
\hline \multirow[t]{5}{*}{ SCI AdV-EGFP } & 30 & Immunohistochemistry, BBB & 10 \\
\hline & 7 & $\begin{array}{l}\text { RT-PCR, western blot, EGFP } \\
\text { fluorescence }\end{array}$ & 5 \\
\hline & 14 & RT-PCR, EGFP fluorescence & 5 \\
\hline & 21 & EGFP fluorescence & 2 \\
\hline & 30 & RT-PCR & 3 \\
\hline \multirow[t]{4}{*}{ SCI AdV-GDNF } & 30 & Immunohistochemistry, BBB & 12 \\
\hline & 7 & RT-PCR, western blot & 3 \\
\hline & 14 & RT-PCR & 3 \\
\hline & 30 & RT-PCR & 3 \\
\hline \multirow{3}{*}{$\begin{array}{l}\mathrm{SCl} \text { (nontransduced } \\
\text { control) }\end{array}$} & 7 & RT-PCR & 3 \\
\hline & 14 & RT-PCR & 3 \\
\hline & 30 & Immunohistochemistry, RT-PCR & 6 \\
\hline Sham AdV-EGFP & 7 & Western blot & 2 \\
\hline Sham AdV-GDNF & 7 & Western blot & 2 \\
\hline
\end{tabular}

Abbreviations: BBB, Basso, Beattie and Bresnahan; RT-PCR, real-time polymerase chain reaction; $\mathrm{SCl}$, spinal cord injury.

impactor was centered above Th8 and dropped from a height of $25 \mathrm{~mm}$ to induce moderate SCI. ${ }^{22}$ Following SCI, some of the rats received an intraspinal injection, and then the dorsal back musculature and the skin were sutured. After the surgical procedure, rats received daily doses of gentamicin (25 mg kg ${ }^{-1}$, Russia) intramuscularly for 7 consecutive days. The bladders of the injured rats were manually emptied twice daily until spontaneous voiding occurred.

\section{Intraspinal injections}

Immediately following SCI, $10 \mu \mathrm{l}$ suspensions of UCB-MCs+AdV-GDNF or UCB-MCs+AdV-EGFP (containing $2 \times 10^{6}$ cells) were injected into two points $\left(5 \mu \mathrm{l}\right.$ per injection; $1 \times 10^{6}$ cells per $5 \mu \mathrm{l}$ ) at the lesion site at a depth of $1 \mathrm{~mm}$ by using a $5-\mu$ l Hamilton syringe. The distance from the point of injection to the epicenter of the injury was $1 \mathrm{~mm}$. The rostral and caudal points were displaced from the midline at a distance of $0.5 \mathrm{~mm}$, respectively, to the left and right. In the direct-gene-delivery groups, the adenoviral vectors AdV-EGFP and AdV-GDNF $\left(3.2 \times 10^{6}\right.$ plaque forming units per $\left.5 \mu \mathrm{l}\right)$ were injected into the aforementioned points. After the intraspinal injections, the wound was sutured.

\section{Immunofluorescence analysis}

Rats were anesthetized with chloral hydrate and intracardiacally perfused with $4 \%$ paraformaldehyde (Sigma) in phosphate-buffered saline (PBS, pH 7.4). Spinal cord pieces (50 $\mathrm{mm}$ long, $2.5 \mathrm{~cm}$ rostral and caudal from the lesion site) were removed and postfixed in $4 \%$ paraformaldehyde at $4{ }^{\circ} \mathrm{C}$ overnight. After incubation in 30\% sucrose, the samples were frozen in liquid nitrogen and embedded in tissue freezing medium, and then $20 \mu \mathrm{m}$ transverse tissue sections were obtained using the cryostat Microm HM 560 (Thermo Scientific, Waltham, MA, USA) and processed as free-floating sections. Table 2 lists the primary and secondary Abs used and their dilutions. For double and triple immunofluorescence labeling, sections were blocked with $5 \%$ normal goat serum for $45 \mathrm{~min}$ at room temperature (RT) and then incubated overnight at $4{ }^{\circ} \mathrm{C}$ with a mixture of primary Abs raised in distinct species. For visualization, fluorophore-conjugated secondary Abs were applied for $2 \mathrm{~h}$ at RT. 4',6Diamidino-2-phenylindole (DAPI) $\left(10 \mu \mathrm{g} \mathrm{ml}^{-1}\right.$ in PBS, Sigma) was used for
Table 2 Primary and secondary antibodies used in immunofluorescent staining

\begin{tabular}{llcl}
\hline Antibody & Host & Dilution & Source \\
\hline HNu & Mouse & $1: 150$ & Millipore \\
GDNF & Rabbit & $1: 100$ & Santa Cruz \\
GFAP & Mouse & $1: 200$ & Santa Cruz \\
S100B & Rabbit & $1: 1200$ & Dako \\
AQP4 & Goat & $1: 200$ & Santa Cruz \\
PDGFoR & Rabbit & $1: 100$ & Santa Cruz \\
Cx47 & Mouse & $1: 100$ & Invitrogen \\
P0 & Goat & $1: 50$ & Santa Cruz \\
Anti-goat IgG conjugated with Alexa 488 & Donkey & $1: 200$ & Invitrogen \\
Anti- rabbit IgG conjugated with Alexa 555 & Donkey & $1: 200$ & Invitrogen \\
Anti- mouse IgG conjugated with Alexa 647 & Donkey & $1: 200$ & Invitrogen \\
\hline
\end{tabular}

Abbreviation: GDNF, glial cell-derived neurotrophic factor.

visualizing nuclei. The blocking serum and the primary and secondary Abs were applied in $0.1 \%$ Triton X-100 in PBS. Coverslips were mounted on slides by using a mounting medium (Vectashield, Vector Labs, Burlingame, CA, USA), and the stained sections were examined using an LSM 780 confocal microscope (Carl Zeiss). The following areas were selected for quantitative and semiquantitative immunohistochemical evaluation of glial cells: the ventral horn $(\mathrm{VH})$, the main corticospinal tract (CST), ventral funiculi (VF), the area around the central canal (CC), and the dorsal root entry zone (DREZ). In the images of these areas, we counted the PDGFoR- and Cx47-immunopositive cells and measured the mean intensity of staining for glial fibrillary acidic protein (GFAP), S100B and AQP4; we used a $\times 40$ objective lens and captured images from 10 adjacent optical slices $\left(512 \times 512\right.$ pixels; observed area, $\left.0.05 \mathrm{~mm}^{2}\right)$. Only PDGFoR- and Cx47-cells that displayed clearly outlined nuclei were evaluated. The mean intensity of labeling in the images (semi-quantitative analysis of GFAP, S100B and AQP4) was analyzed using the software Zen 2012 (Carl Zeiss). All sections were imaged in the $z$-plane by using identical confocal settings (laser intensity, gain, offset). Measurements were obtained from histological sections collected at $200 \mu \mathrm{m}$ increments extending 5 and $10 \mathrm{~mm}$ in the rostral direction from the epicenter of the SCI.

\section{Morphometric analysis of the spinal cord}

Spinal cords were removed and fixed in a $2.5 \%$ solution of glutaraldehyde, after which they were incubated in a $1 \%$ solution of osmium tetroxide and embedded into an epoxy resin mixture (Epon/Araldit). Toluidine blue staining was used for visualizing tissues, and images were captured using a $\times 4$ objective lens and a microscope (Axio Lab.A1, Carl Zeiss) equipped with a digital camera (AxioCam HRc, Carl Zeiss). The cross-sectional area of the spared tissue was measured on semithin sections of the spinal cord within the midpoint of the lesion center (the epicenter) and in spinal segments 3 and $5 \mathrm{~mm}$ rostral and caudal to the injury site. ImageTool application version 3.0 was used for measuring the tissue area. The spared myelinated fibers were counted in the outer area of the lateral funiculi within the frontal plane passing through the central canal from both sides (LF, $S=0.09 \mathrm{~mm}^{2}, \times 25$ objective) (Figure 1c').

\section{RNA extraction and real-time PCR of EGFP and GDNF}

Total RNA was extracted from freshly isolated spinal cords by using Yellow Solve reagents (Silex, Russia) according to the manufacturer's protocol. The first strand of cDNA was synthesized using $200 \mathrm{U}$ of RevertAid Reverse Transcriptase. For cDNA synthesis, an RNA/primer/dNTP mixture containing $100 \mathrm{ng}$ of RNA, $0.5 \mu \mathrm{l}$ of Random hexamer primers (Litekh, Russia), and $8.5 \mu \mathrm{l}$ of $\mathrm{H}_{2} \mathrm{O}$ was denatured at $65^{\circ} \mathrm{C}$ for $5 \mathrm{~min}$ and chilled to $4{ }^{\circ} \mathrm{C}$; cDNA was synthesized using $200 \mathrm{U}$ of RevertAid Reverse transcriptase and $20 \mathrm{U}$ of Ribolock RNase inhibitor (Thermo Scientific, USA) in a 20- $\mu$ reaction mixture. After incubation for $10 \mathrm{~min}$ at $25^{\circ} \mathrm{C}$, the reaction was continued for another $60 \mathrm{~min}$ at $42^{\circ} \mathrm{C}$ and then terminated by heating at $70^{\circ} \mathrm{C}$ for $10 \mathrm{~min}$. 
a

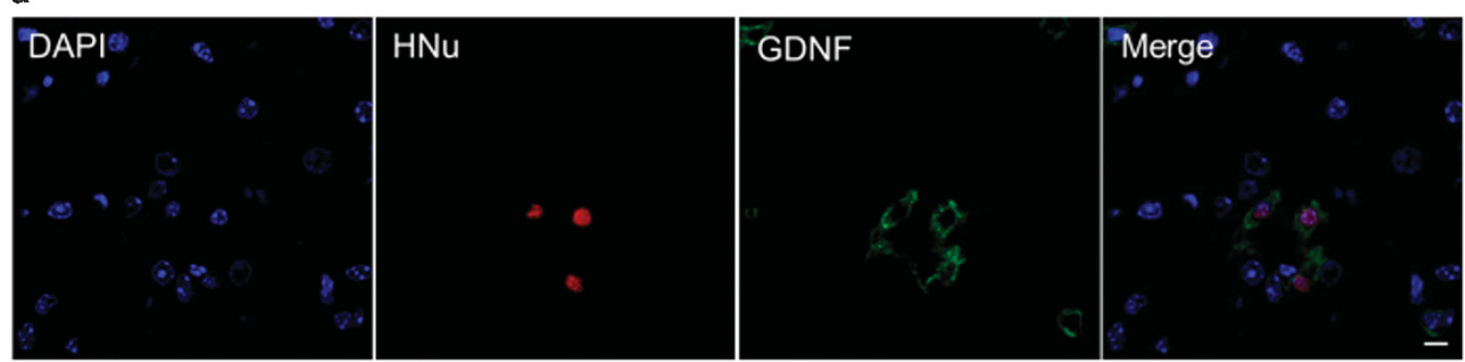

b
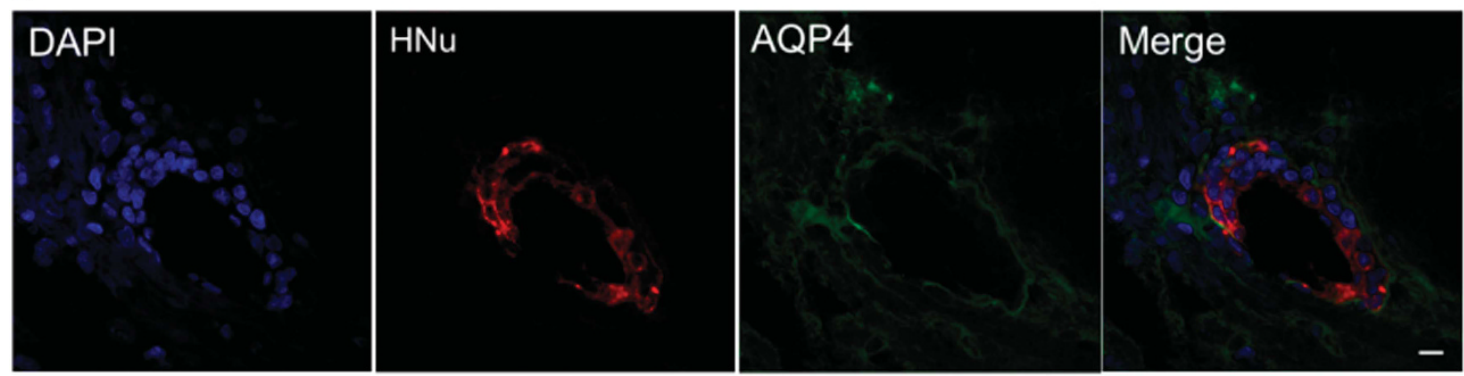

C
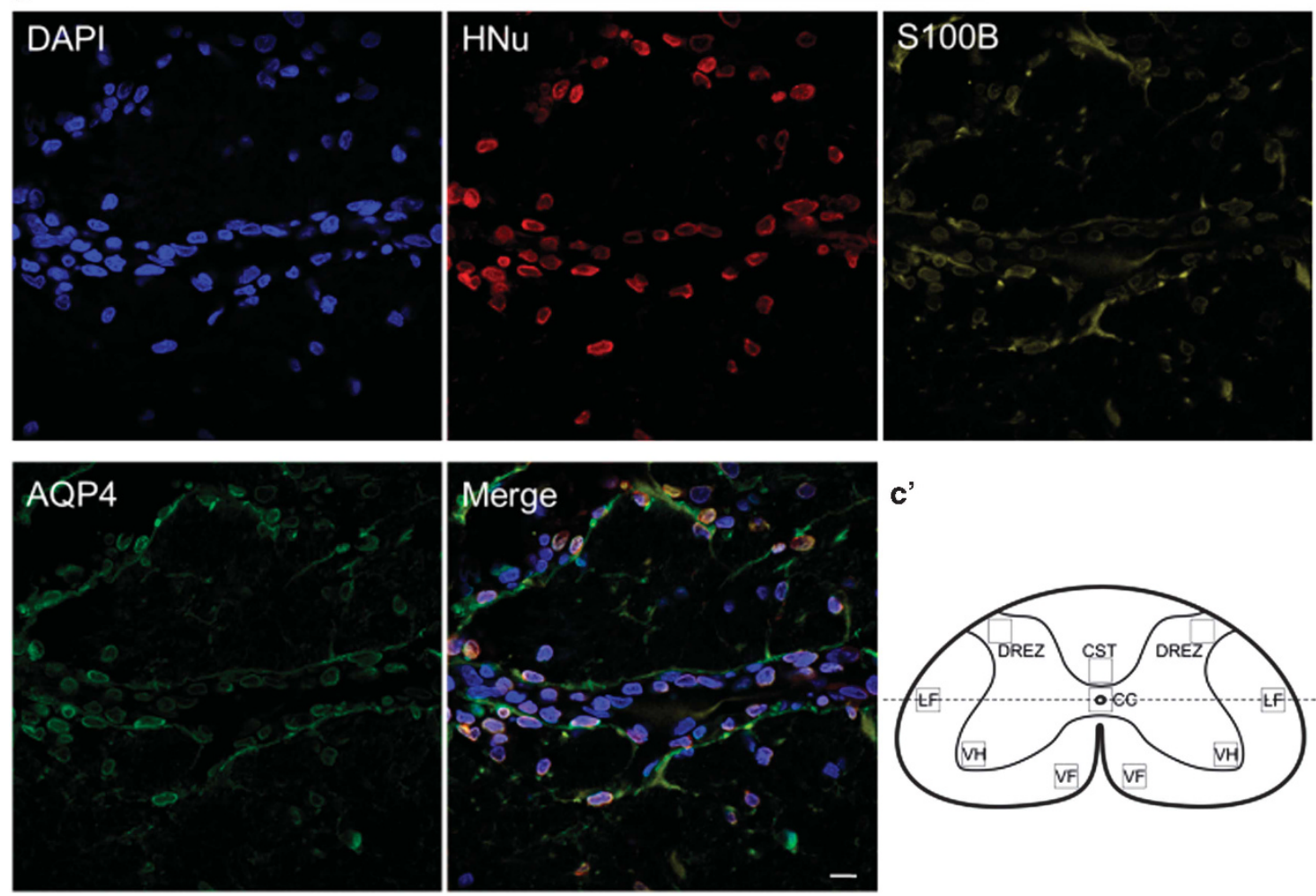

c'

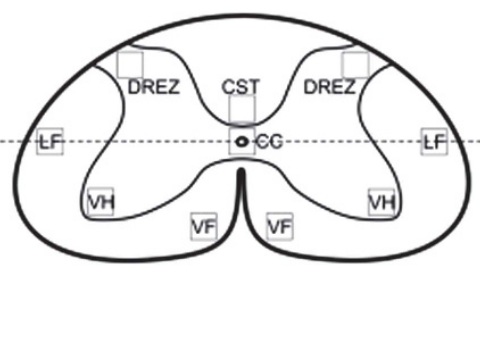

Figure 1 Visualization of grafted cells in the spinal cord at 30 days after transplantation of UCB-MCs+AdV-EGFP (a) and UCB-MCs+AdV-GDNF (b). (a) HNu ${ }^{+}$/ $\mathrm{GDNF}^{+}$cells in the dorsal funiculus, $10 \mathrm{~mm}$ caudal to the contusion epicenter. Nuclei are stained with DAPI (blue). (b) $\mathrm{HNu}^{+}$cells (red) in the gray matter on the border with the corticospinal tract, $5 \mathrm{~mm}$ caudal to the epicenter. The figure shows $\mathrm{HNu}^{+}$cells arranged around the cystic cavity and surrounded by $\mathrm{AQP}^{+}$astrocytes. (c) Survival and differentiation of grafted UCB-MCs in the injured spinal cord at a site $10 \mathrm{~mm}$ caudal to the epicenter on Day 30 after injury and immediate transplantation of UCB-MCs+AdV-EGFP. The figure shows quadruple labeling of cells with Abs against HNu (red, Alexa 647), S100B (yellow, Alexa 555), and AQP4 (green, Alexa 488) and with DAPI (blue, nuclei), and provides evidence that the grafted UCB-MCs might differentiate along an astrocyte lineage $\left(\mathrm{S}_{100 \mathrm{~B}^{+}}\right.$and $\mathrm{AQP} 4^{+}$cells). (c') In the rat spinal cord, six areas were selected for histological and immunohistochemical evaluation: the ventral horn (VH), the main corticospinal tract (CST), the ventral funiculi (VF), the area of the central canal (CC), the outer area of the lateral funiculi on a line passing through the central canal (LF), and the dorsal root entry zone (DREZ). Scale bar: 10 (a, c) and 5 (b) $\mu \mathrm{m}$. 
TaqMan real-time PCR. Samples of the obtained cDNAs were analyzed using a CFX 96 Real-Time PCR System (Bio-Rad). Each PCR reaction $(15 \mu \mathrm{l})$ contained $0.5 \mu$ l of cDNA, $2.5 \times$ reaction mixture B (Syntol, Russia), $200 \mathrm{~nm}$ of each primer, and the probe (100 nM) (Table 3$)$. The primers and probes used for qPCR assays performed on GDNF and VEGF genes were designed based on the mRNAs of human GDNF and VEGF by using tools developed by the company GenScript. The primers designed for $18 \mathrm{~S}$ rRNA are suitable for performing real-time PCR on the rRNA from rat, mouse and human. The following amplification parameters were used: preheating at $95^{\circ} \mathrm{C}$ for $3 \mathrm{~min}$, followed by 39 cycles of $95^{\circ} \mathrm{C}$ for $10 \mathrm{~s}$ and $55^{\circ} \mathrm{C}$ for $15 \mathrm{~s}$ including the plateread. RNA amounts were normalized relative to $18 \mathrm{~S}$ ribosomal RNA (considered as a housekeeping gene). Standard curves for relative quantitation of EGFP, VEGF and GDNF were generated using serial dilutions of plasmid DNAs containing the corresponding cDNA inserts. The gene expression level after SCI (nontransduced control, NTC) was considered as 100\%. All RT-PCRs were performed in triplicate.

\section{Western blotting}

Total protein from spinal cords was extracted by homogenizing and sonicating the tissue in RIPA buffer (Sigma). Extracts were centrifuged at $16000 \times \mathrm{g}$ for $20 \mathrm{~min}$ at $4{ }^{\circ} \mathrm{C}$ and then the protein concentrations in the supernatants were determined using a BCA kit (Thermo Scientific). The protein lysates $(40 \mu \mathrm{g})$ were subjected to $4-13 \%$ gradient SDS-PAGE and then transferred to polyvinylidene fluoride membranes, which were blocked for $4 \mathrm{~h}$ at RT in 5\% non-fat dry milk in PBS $/ 0.5 \%$ Tween 20 . The membranes were washed thrice in PBS $/ 0.5 \%$ Tween 20 and then incubated $\left(18 \mathrm{~h}, 4^{\circ} \mathrm{C}\right)$ with rabbit anti-GDNF (1:200, Santa Cruz) or goat anti-GFP (1:400, GenScript) Abs. The antigen-Ab

Table 3 Primers and probes for RT-PCR

\begin{tabular}{ll}
\hline Primer & Nucleotide sequence \\
\hline GDNF-TM-forward & CGCTGAGCAGTGACTCAAAT \\
GDNF-TM-reverse & CGATTCCGCTCTCTTCTAGG \\
GDNF-TM-probe & [FAM]TCCATGACATCATCGAACTGATCAGG[BH1] \\
18S-TM-forward & GCCGCTAGAGGTGAAATCTTG \\
18S-TM-reverse & CATTCTTGGCAAATGCTTTCG \\
18S-TM-probe & [HEX]ACCGCGCAAGACGGACCAG[BH2] \\
EGFP-TM-forward & AGCAAAGACCCCAACGAGAA \\
EGFP-TM-reverse & GGCGGCGGTCACGAA \\
EGFP-TM-probe & [FAM]CGCGATCACATGGTCCTGCTGG[BH1] \\
\hline
\end{tabular}

Abbreviation: GDNF, glial cell-derived neurotrophic factor.
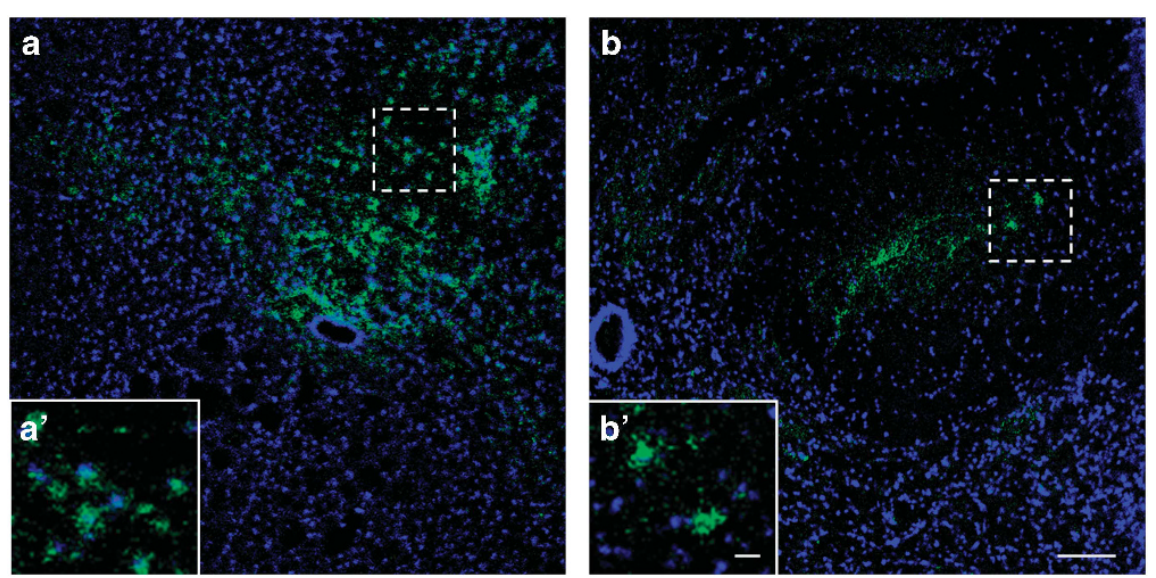

Figure 2 Injured spinal cord at 7 (a) and 14 (b) days after direct injection of AdV-EGFP. Cells labeled with EGFP (green) appeared in the white matter of the dorsal funiculus and adjacent to the gray matter at 7 days after injury (a), and cells labeled with comparatively less intensity appeared predominantly in the white matter along the dorsal median sulcus at 14 days after injury (b). Nuclei are stained with DAPI (blue). Enlarged boxed areas in a and $\mathbf{b}$ are shown in $\mathbf{a}$ ' and 'b'. Scale bar: $100(\mathbf{a}, \mathbf{b})$ and $10\left(\mathbf{a}^{\prime}, \mathbf{b}^{\prime}\right) \mu \mathrm{m}$. complexes were detected using horseradish (HRP)-conjugated goat anti-rabbit IgG or mouse anti-goat IgG (Sigma) and developed by using an ECL Western Blotting substrate kit (HRP) according to the manufacturer's instructions (Life Technologies, Carlsbad, CA, USA).

\section{Behavioral test}

Locomotor recovery was assessed in an open field by using the BBB rating scale. The baseline was obtained on the day before SCI. After injury, each rat was tested on Days 7, 9, 11, 13, 15, 17, 19, 21, 23, 25, 27 and 29 in order to evaluate differences in functional recovery among the experimental groups. Locomotion was scored simultaneously by two observers who were blinded to the treatment groups.

\section{Statistical analysis}

Data are expressed as means \pm standard error of the mean (s.e.m.). We used Student's $t$-test distribution or a one-way analysis of variance (ANOVA) with significant. All analyses were performed in a blinded manner with respect to the treatment group. Data were analyzed using Origin 7.0 SR0 (OriginLab, Northampton, MA, USA) software.

\section{RESULTS}

\section{Distribution and survival of transplanted UCB-MCs}

We used anti-HNu and anti-GDNF Abs to visualize the grafted UCBMCs+AdV-GDNF in the spinal cord. $\mathrm{HNu}^{+} / \mathrm{GDNF}^{+}$cells were observed in the gray and white matter at 30 days after SCI and delivery of UCB-MCs+AdV-GDNF. $\mathrm{HNu}^{+} / \mathrm{GDNF}^{+}$cells were detected predominantly in the dorsal funiculus and horns (Figure 1a). Immunofluorescence labeling revealed that $\mathrm{HNu}^{+} / \mathrm{GDNF}^{+}$cells migrated up to $10 \mathrm{~mm}$ from the epicenter of the UCB-MCs+AdV-GDNF injection in the rostral and caudal directions.

For UCB-MC phenotyping, the anti-HNu $\mathrm{Ab}$ was used in combination with Abs against the markers $\mathrm{S} 100 \mathrm{~B}$ and $\mathrm{AQP} 4 . \mathrm{HNu}^{+}$/ $\mathrm{S}_{100 \mathrm{~B}^{+} / \mathrm{AQP}^{+}}{ }^{+}$cells were observed in the dorsal funiculus at 30 days after SCI and delivery of UCB-MCs+AdV-EGFP, which provided evidence that the grafted cells might differentiate along an astrocyte lineage $\left(\mathrm{S}_{100 \mathrm{~B}^{+}}\right.$and $\mathrm{AQP} 4{ }^{+}$cells) (Figure $\left.1 \mathrm{c}\right)$. We observed that in the rats of the UCB-MCs+AdV-EGFP group, $\mathrm{HNu}^{+}$cells were arranged around a cavity and were surrounded by astrocytes expressing AQP4 in the gray matter (at the boundary with the corticospinal tract) at a distance of $5 \mathrm{~mm}$ from the SCI epicenter in the caudal direction (Figure 1b). Tukey's test for multiple groups. A value of 0.05 was considered statistically 
Intense EGFP fluorescence was observed 7 days after SCI and delivery of AdV-EGFP in the dorsal funiculus and surrounding gray matter (Figure 2a), which indicated that the adenovirus had transduced the host cells of the spinal cord. We also detected local EGFP fluorescence along the posterior median sulcus at 14 (Figure $2 \mathrm{~b}$ ) and 21 days after SCI and delivery of AdV-EGFP. Single EGFP ${ }^{+}$cells were observed in both gray and white matter at 30 days after SCI and delivery of AdV-EGFP; mostly $\mathrm{EGFP}^{+}$cells were detected in the dorsal funiculus and the adjacent gray matter that corresponded to the site of injection of AdV-EGFP.

\section{Tissue sparing}

At the end of the first week, edema was detected in the gray matter in the spinal cord contusion area in all SCI groups. Severe nerve-fiber degeneration was observed in the area of trauma, and also in adjacent areas rostral and caudal to the injury site. Myelin sheath destruction was noticeable in the white matter, and maximal damage occurred in the gray matter, where chromatolysis and neuronal death were observed. A central zone of completely disintegrated tissue appeared as a large cavity containing dispersed fragments of degenerated cells; the extent of the central zone decreased substantially with an increase in the distance from the injury epicenter: at $3 \mathrm{~mm}$, it was approximately two-thirds of the total cross-sectional area, and at $5 \mathrm{~mm}$, up to half of the area. By comparison, at the white matter periphery, tissue was more preserved and signs of destruction were less pronounced. We detected an abundance of micro-cavities separated by layers of connective tissue showing evidence of astrogliosis. Tissue destruction in the injury epicenter did not differ in any of the control (UCB-MCs a

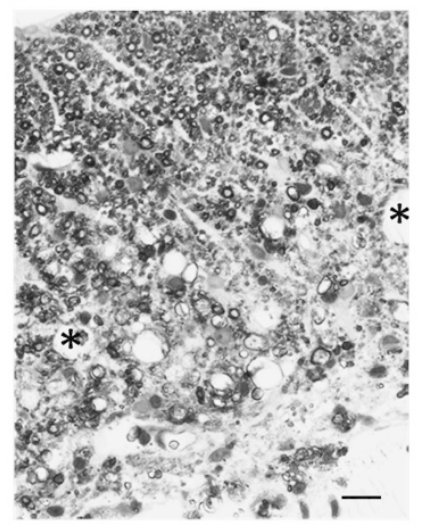

c

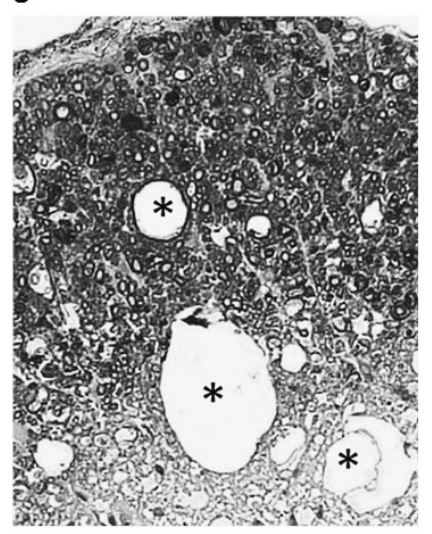

b

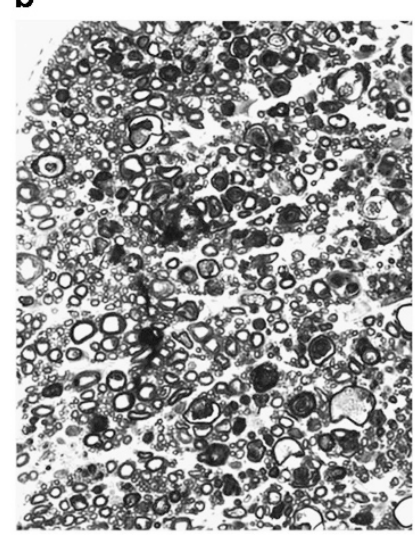

d

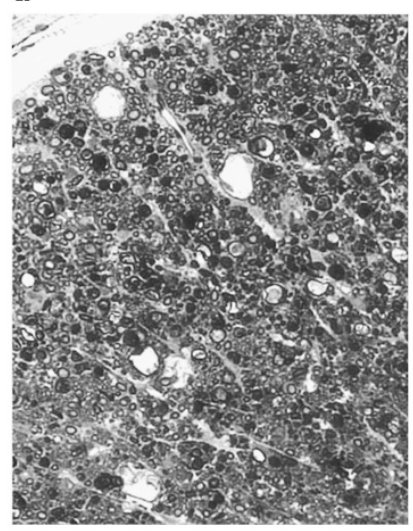

e

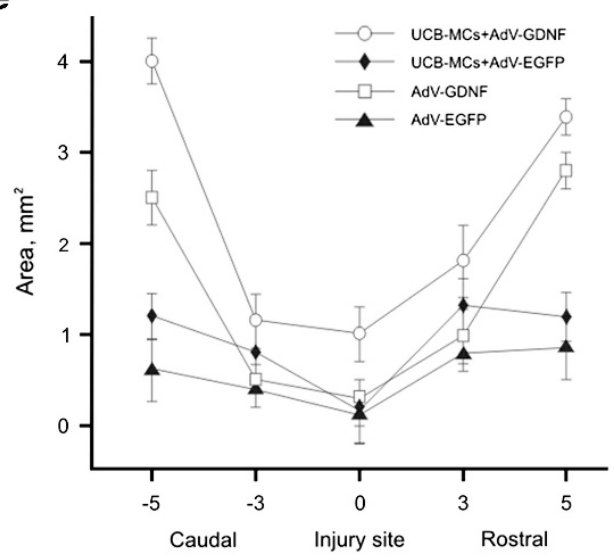

f

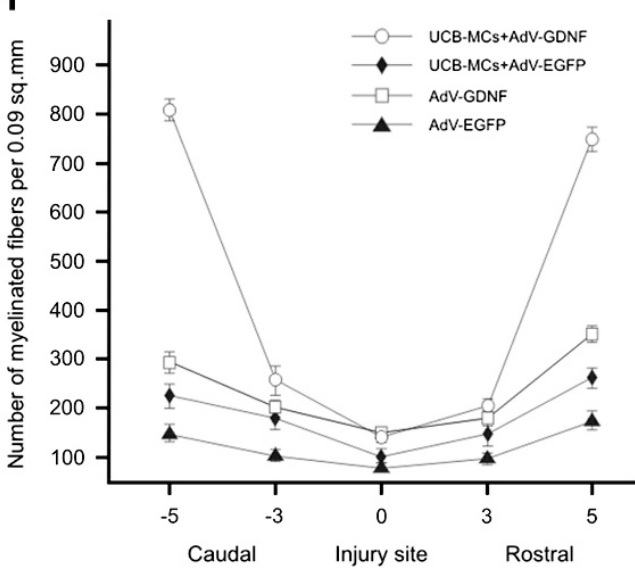

Figure 3 Fragments of white matter in the outer area of the lateral funiculus (LF) on a line passing through the central canal at Day 30 post injury. (a) UCBMCs+AdV-EGFP, (b) UCB-MCs+AdV-GDNF, (c) AdV-EGFP and (d) AdV-GDNF. In the material collected from the UCB-MCs+AdV-GDNF group (b), more intact myelinated fibers displaying clearly defined outlines and a minimal number of cystic cavities (asterisks) are observed than in the other groups, and this corresponds to superior tissue sparing as compared with that in the other groups. The images are of toluidine blue-stained semithin sections. Scale bar: $50 \mu \mathrm{m}$. (e) Tissue preservation $\left(\mathrm{mm}^{2}\right.$ ) assessed by analyzing the cross-sectional area of the spinal cord within the epicenter (injury site) and in spinal segments 3 and $5 \mathrm{~mm}$ rostral and caudal to the epicenter at Day 30 post injury. Tissue sparing in segments $5 \mathrm{~mm}$ rostral and caudal to the injury in the UCB-MCs+AdV-GDNF $(P<0.001)$ and AdV-GDNF $(P<0.001)$ groups was significantly higher than that in UCB-MCs+AdV-EGFP and AdV-EGFP groups, respectively. At the injury epicenter, the value of the index area of spared tissue was significantly higher $(P<0.05)$ in the UCB-MCS+AdV-GDNF group than in the UCB-MCs+AdV-EGFP group. Means \pm s.e.m. are shown. (f) The average number of spared myelinated fibers in the outer area of the right lateral funiculi (LF) of spinal segments 3 and $5 \mathrm{~mm}$ rostral and caudal to the lesion epicenter at Day 30 post injury. The number was significantly higher in the segments $5 \mathrm{~mm}$ rostral and caudal to the epicenter in the animals of the UCB-MCs+AdV-GDNF and AdV-GDNF groups when compared with that in the animals of the UCB-MCs+AdV-EGFP and AdV-EGFP groups, respectively $(P<0.001)$, and in the segments $3 \mathrm{~mm}$ rostral and caudal to the epicenter in the AdV-GDNF group when compared with that in the AdV-EGFP group $(P<0.05)$. The number of spared fibers in the injury site was also higher in the AdV-GDNF group than in the AdV-EGFP group $(P<0.05)$. A full color version of this figure is available at the Spinal Cord journal online. 
+AdV-EGFP, AdV-EGFP) or treatment groups (UCB-MCs+AdVGDNF, AdV-GDNF).

At Day 30, compared with the UCB-MCs+AdV-EGFP group, the UCB-MCs+AdV-GDNF group showed a 30\% reduction in the crosssectional area of damaged tissue at a distance of $3 \mathrm{~mm}$ from the injury epicenter in the rostral direction and a $27 \%$ reduction in the caudal direction; at a distance of $5 \mathrm{~mm}$ from the epicenter, these values were $70 \%$ and $65 \%$, respectively (Figures $3 \mathrm{a}, \mathrm{b}$ and e).

By 30 days after injury and injection of the recombinant adenovirus AdV-GDNF into the lesion zone, tissue loss was decreased at a distance of $3 \mathrm{~mm}$ from the injury epicenter by $20 \%$ and $17 \%$ in the rostral and caudal directions, respectively. At a distance of $5 \mathrm{~mm}$ from the epicenter, the reduction in tissue loss was more pronounced: it was decreased by $75 \%$ and $70 \%$ in the rostral and caudal directions, respectively, as compared with that in the control group of the animals that were injected with the recombinant adenovirus AdV-EGFP (Figures 3c-e).

\section{Analysis of myelinated fibers}

In the UCB-MCs+AdV-GDNF group, the number of spared myelinated fibers in the LF exceeded that in the corresponding area in the UCB-MCs+AdV-EGFP group. This excess was recorded at the injury epicenter (1.4 fold, $P>0.05$ ), at a distance of $3 \mathrm{~mm}$ from the epicenter in both directions ( 1.4 fold, $P<0.05)$, and at $5 \mathrm{~mm}$ from the epicenter in the rostral $(2.9$ fold, $P<0.001)$ and caudal (3.6 fold, $P<0.001$ ) directions (Figure 3f).

In the aforementioned area, the preservation of myelinated fibers was also higher after AdV-GDNF injection than after AdV-EGFP injection (Figures $6 \mathrm{c}$ and $\mathrm{d}$ ). In the AdV-GDNF group, the number of spared myelinated fibers was higher (relative to control) in the injury epicenter (1.9 fold, $P<0.05)$, at $3 \mathrm{~mm}$ from the epicenter in the rostral (1.8 fold, $P<0.05)$ and caudal $(2.0$ fold, $P<0.05)$ directions, and at $5 \mathrm{~mm}$ in both directions ( 2.0 fold, $P<0.001$ ) from the injury epicenter (Figure 3f).

Adenoviral vector-mediated gene transfer of GDNF reversed the degeneration of myelinated fibers in the contused rat spinal cord. This effect was observed after transplantation of transduced human UCBMCs and also after direct gene therapy. However, UCB-MC-mediated GDNF gene delivery was more effective than direct injection of the GDNF gene. In the LF, at $5 \mathrm{~mm}$ from the injury epicenter, 2.1-2.6 times more myelinated fibers were present after cell-mediated GDNF gene delivery than after direct injection of the GDNF gene $(P<0.001)$. Moreover, at a distance of $3 \mathrm{~mm}$ from the epicenter in the caudal direction, the number of spared myelinated fibers in the cell-mediated GDNF gene-delivery group (UCB-MCs+AdV-GDNF) was 1.3 times higher $(P<0.05)$ than that in the group injected directly with the GDNF gene (AdV-GDNF).

\section{Immunofluorescence analysis}

Astrocytes. We evaluated the distributions of astrocyte populations expressing GFAP, S100B and AQP4. Astrocytes were detected in the DREZ, VH and VF at a distance of $10 \mathrm{~mm}$ from the SCI epicenter in the rostral direction.

GFAP. The highest mean intensity of GFAP labeling was detected in the UCB-MCs+AdV-GDNF group in the VH and VF, and the difference compared with the other groups was statistically significant $(P<0.05)$ (Figure $4 \mathrm{a})$. The mean intensity of GFAP labeling was significantly higher in the DREZ of the UCB-MCs+AdV-GDNF, UCBMCs+AdV-EGFP and AdV-GDNF groups than in the DREZ of the intact control group. Our results showed that cell-mediated GDNF
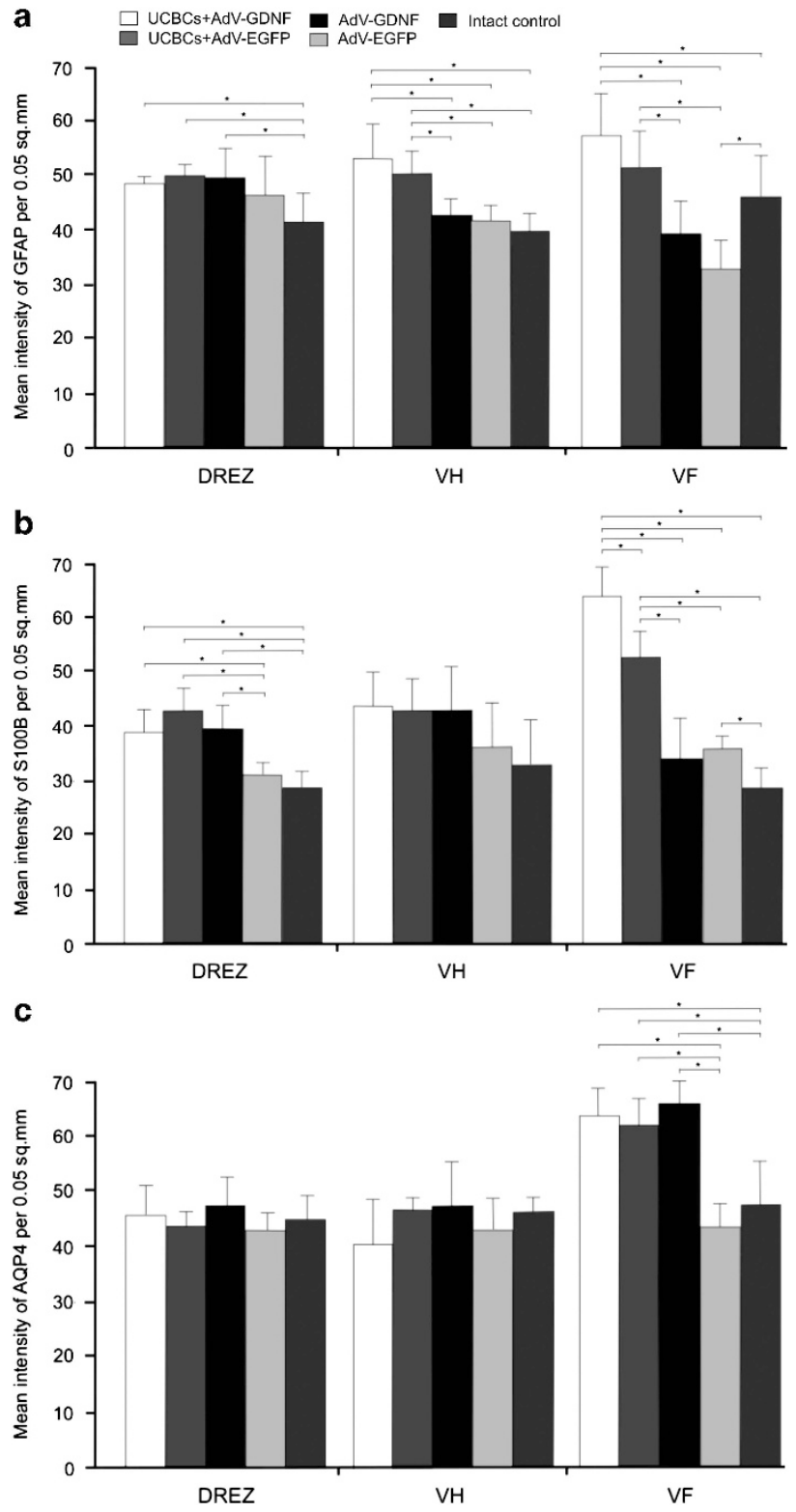

Figure 4 Mean labeling intensity of GFAP (a), S100B (b) and AQP4 (c) in the DREZ, VH and VF of the animals in the UCB-MCs+AdV-GDNF, UCB-MCs + AdV-EGFP, AdV-GDNF, AdV-EGFP and intact control groups, at a distance of $10 \mathrm{~mm}$ from the $\mathrm{SCl}$ epicenter in the rostral direction. Our results showed that cell-mediated GDNF gene delivery (UCB-MCs+AdV-GDNF) exerted a stronger influence on GFAP expression after SCI in the VH and the VF and on S100B expression in the VF than did direct delivery. However, transplantation of transgenic human UCB-MCs and direct gene therapy affected GFAP expression equally in the DREZ and the VH. The content of AQP4 in astrocytes was more stable than those of the other proteins tested, and the expression of AQP4 was affected by GDNF gene delivery to a lesser extent than was the expression of other proteins. Differential changes in the expression of GFAP, S100B, and AQP4 are shown. ${ }^{*} P<0.05$, one-way ANOVA. A full color version of this figure is available at the Spinal Cord journal online.

gene delivery (UCB-MCs+AdV-GDNF) exerted a stronger effect on GFAP expression after SCI in the VH and the VF. However, GFAP expression was increased only in the white matter (VF) of the UCBMCs+AdV-GDNF group when compared with that in the intact control group. 
S100B. The mean intensity of S100B labeling was highest in the VF of the UCB-MCs+AdV-GDNF group, and the difference compared with the other groups was statistically significant $(P<0.05)$ (Figure $4 \mathrm{~b}$ ). Intriguingly, the mean intensity of GFAP and S100B labeling in the VF was different in the intact control and AdV-EGFP groups; whereas GFAP expression in the VF of the intact control group was significantly higher than that measured in the AdV-EGFP group, $\mathrm{S} 100 \mathrm{~B}$ expression in the VF of the intact control group was significantly lower than that measured in the AdV-EGFP group. Moreover, S100B expression in the DREZ differed in a statistically significant manner between the experimental groups (UCB-MCs +AdV-GDNF; AdV-GDNF; UCB-MCs+AdV-EGFP) and the control groups (AdV-EGFP; intact control). Our results showed that cellmediated GDNF gene delivery (UCB-MCs+AdV-GDNF) more strongly affected S100B expression after SCI in the VF than did direct delivery. However, transplantation of transgenic human UCB-MCs and direct gene therapy affected GFAP expression equally in the DREZ and the $\mathrm{VH}$.

AQP4. The mean intensity of AQP4 labeling was higher in the VF of the UCB-MCs+AdV-GDNF, UCB-MCs+AdV-EGFP and AdV-GDNF groups than in the VF of the intact control and the AdV-EGFP groups (Figure 4c). However, in the DREZ and the VH, AQP4 expression did not differ significantly between any of the groups. This suggests that the AQP4 expression level in astrocytes was more stable than that of the proteins examined and that AQP4 was affected by GDNF gene delivery to a lesser extent than the other proteins were.
Oligodendrocytes. Oligodendrocytes were detected-based on PDGFoR and Cx47 expression-in the DREZ, VH and VF at 5 and $10 \mathrm{~mm}$ from the SCI epicenter in the rostral direction.

PDGF $\boldsymbol{\alpha} R$. PDGF $\alpha \mathrm{R}$, a specific marker of oligodendrocyte precursor cells, ${ }^{23}$ was detected in the DREZ, VH, CST, CC and VF of the UCBMCs+AdV-GDNF, UCB-MCs+AdV-EGFP, AdV-GDNF, AdV-EGFP and SCI groups at a distance of $5 \mathrm{~mm}$ from the SCI epicenter in the rostral direction (Figure 5). In the UCB-MCs+AdV-GDNF group, the number of PDGF $\alpha \mathrm{R}^{+}$cells was significantly increased in every studied area when compared with numbers in the AdV-GDNF and AdVEGFP groups $(P<0.05)$. Moreover, the expression in the VF differed in a statistically significant manner between the AdV-GDNF and AdVEGFP groups $(P<0.05)$. Our results showed that cell-mediated delivery of GDNF supported a higher population of $\mathrm{PDGF}^{+} \mathrm{R}^{+}$cells than direct delivery did.

Cx47. $\mathrm{Cx} 47$ is expressed in oligodendrocytes and in a few $\mathrm{S} 100 \mathrm{~B}^{+}$ astrocytes. ${ }^{24} \mathrm{Cx} 47^{+}$cells were detected in the DREZ, VH and VF of all groups. The maximal number of $\mathrm{Cx} 47^{+}$cells was observed in the $\mathrm{VH}$ of the UCB-MCs+AdV-GDNF group and the difference compared with the other groups was statistically significant $(P<0.05)$ (Figure 6a). The number of $\mathrm{Cx} 47^{+}$cells was higher in the DREZ, $\mathrm{VH}$ and VF of the UCB-MCs+AdV-GDNF and AdV-GDNF groups than that in the corresponding areas in the AdV-EGFP group. The number of $\mathrm{Cx}_{4} 7^{+}$cells was the highest in the DREZ of the intact control group, and this was significantly different from the number in the AdV-EGFP group. Fewer $\mathrm{Cx} 47^{+}$cells were detected in the $\mathrm{VH}$ of
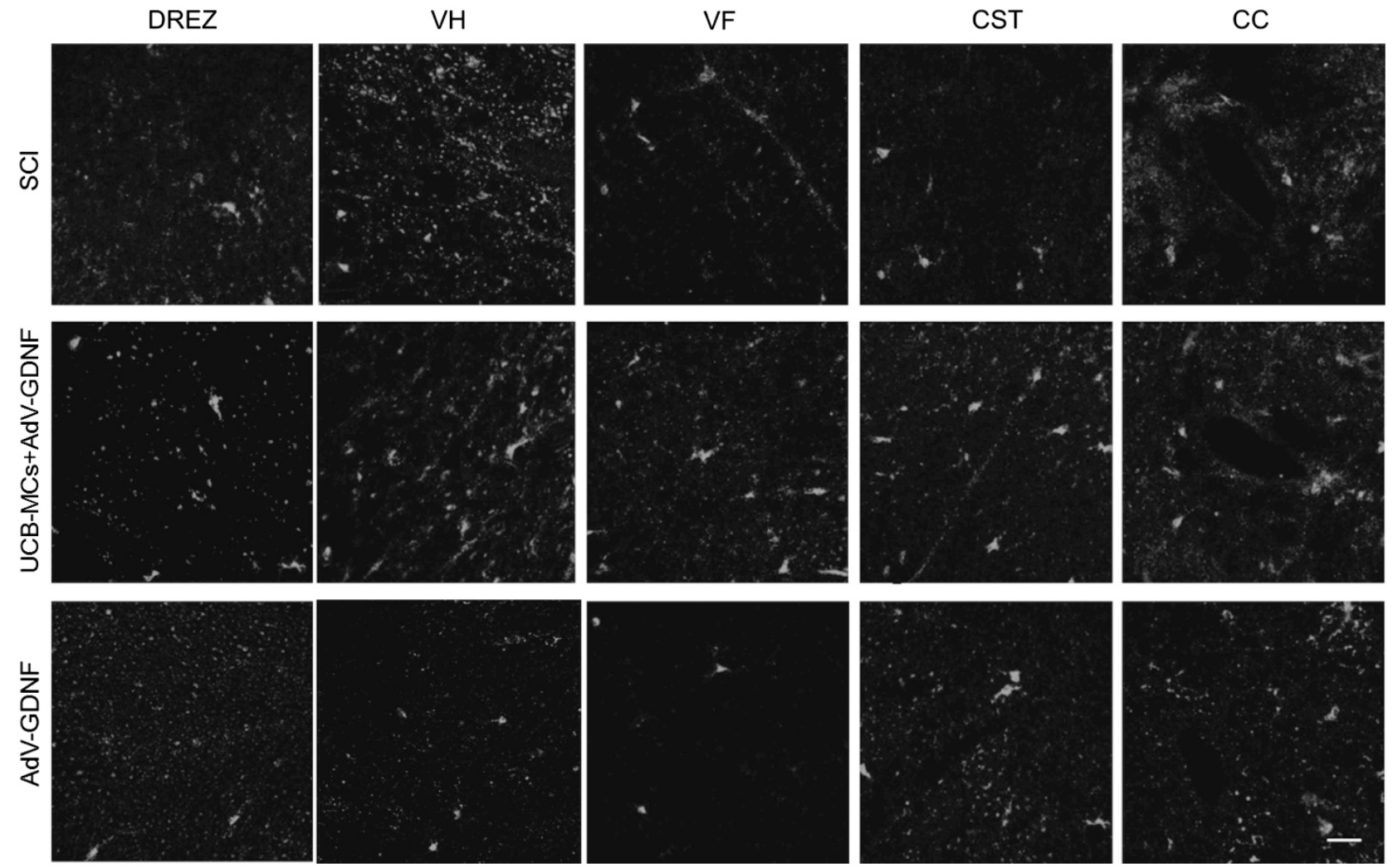

Figure 5 Differential changes in the expression of PDGF $\alpha$ R (red) at a distance of $5 \mathrm{~mm}$ from the $\mathrm{SCl}$ epicenter in the rostral direction. Dorsal root entry zone (DREZ), ventral horn (VH), ventral funiculi (VF), corticospinal tract (CST) and central canal (CC) (vertical columns) were analyzed in the UCB-MCs+AdVGDNF, AdV-GDNF and SCl rats (horizontal columns). Our results showed that cell-mediated GDNF delivery supported a higher population of PDGF $\alpha \mathrm{R}^{+}$cells than did direct delivery. Confocal microscopy images are shown, each of which was generated by merging channels. Scale bar: $20 \mu \mathrm{m}$. A full color version of this figure is available at the Spinal Cord journal online. 

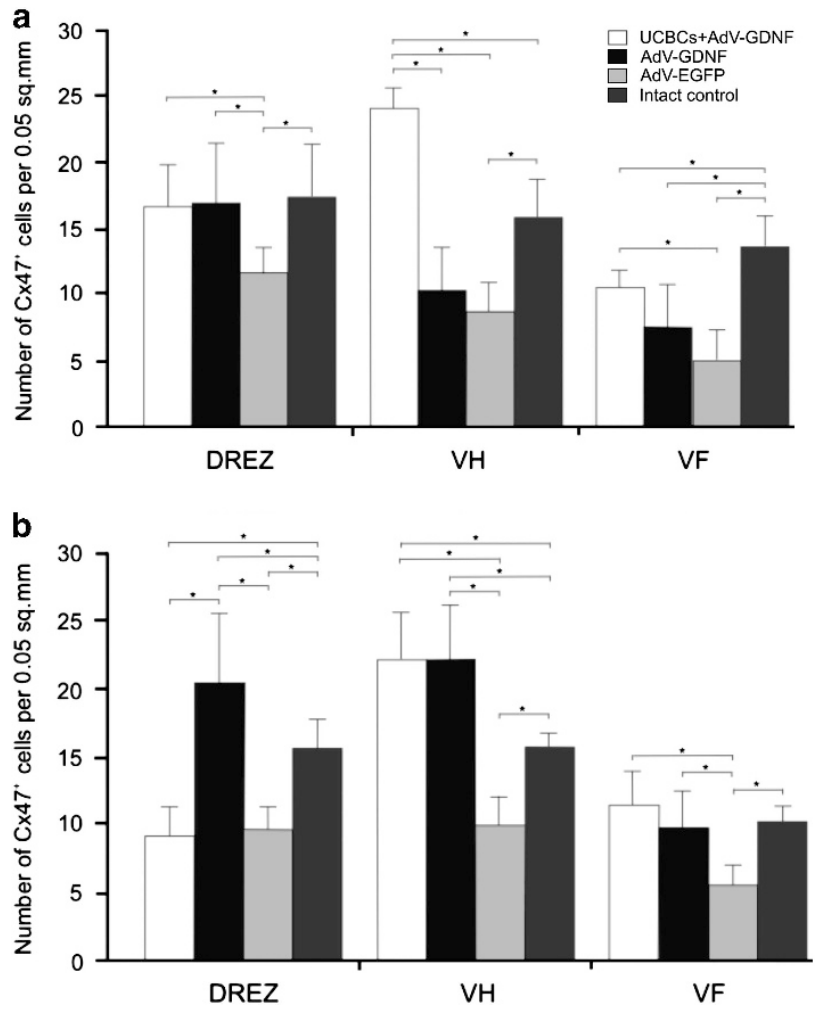

Figure 6 Number of $\mathrm{C} \times 47^{+}$cells in the DREZ, VH and VF of the UCB-MCs + AdV-GDNF, AdV-GDNF, AdV-EGFP and intact control groups at a distance of $5 \mathrm{~mm}$ (a) and $10 \mathrm{~mm}$ (b) from the $\mathrm{SCl}$ epicenter in the rostral direction. Cell-mediated delivery of the GDNF gene more strongly affected the number of $\mathrm{C} \times 47^{+}$cells in all investigated areas near the injury epicenter than did direct delivery. Conversely, direct adenoviral vector-mediated delivery of the GDNF gene exerted a strong influence on the number of $\mathrm{C} \times 47^{+}$cells in the DREZ at a distance of $10 \mathrm{~mm}$ from the SCl epicenter in the rostral direction. Differential changes in the expression of $\mathrm{Cx} 47$ are shown. ${ }^{*} P<0.05$, oneway ANOVA. A full color version of this figure is available at the Spinal Cord journal online.

the AdV-GDNF and AdV-EGFP groups than in the VH of the intact control group. However, the number of $\mathrm{Cx} 47^{+}$cells was higher in the $\mathrm{VH}$ of the UCB-MCs+AdV-GDNF group than in the VH of the intact control group.

The highest number of $\mathrm{Cx} 47^{+}$cells was measured in the $\mathrm{VH}$ of the UCB-MCs+AdV-GDNF and AdV-GDNF groups at a distance of $10 \mathrm{~mm}$ from the SCI epicenter in the rostral direction (Figure 6b). The number of $\mathrm{Cx} 47^{+}$cells was increased in a statistically significant manner in the $\mathrm{VH}$ of groups that received GDNF gene delivery when compared with that in the control groups. The number of $\mathrm{Cx} 47^{+}$cells was significantly higher in the DREZ of the AdV-GDNF group than in the DREZ of the UCB-MCs+AdV-GDNF, AdV-EGFP and intact control groups $(P<0.05)$. However, the number of $\mathrm{Cx} 47^{+}$cells was significantly higher increased in the VF of the UCB-MCs+AdVGDNF, AdV-GDNF and intact control groups than in the VF of the AdV-EGFP group $(P<0.05)$.

The number of $\mathrm{Cx} 47^{+}$cells decreased in the DREZ of the UCBMCs+AdV-GDNF group with an increase in the distance from the injury epicenter in the rostral direction. However, the number of $\mathrm{Cx} 47^{+}$cells increased in the DREZ, VH and VF of the AdV-GDNF group with an increase in the distance from the injury epicenter in the rostral direction. Thus, compared with direct delivery, cell-mediated delivery of the GDNF gene exerted a stronger influence on the number of $\mathrm{Cx} 47^{+}$cells in all investigated areas near the injury epicenter. However, direct adenoviral vector-mediated delivery of the GDNF gene strongly affected the number of $\mathrm{Cx} 47^{+}$cells in the DREZ at a distance of $10 \mathrm{~mm}$ from the SCI epicenter in the rostral direction.

Schwann cells. A specific marker of myelinating Schwann cells, protein zero ( $\mathrm{P} 0)$, was detected in the spinal cord at 30 days after injury in the UCB-MCs+AdV-GDNF, UCB-MCs+AdV-EGFP, AdVGDNF and AdV-EGFP groups (Figure 7). Axons surrounded by $\mathrm{P}^{+}$ myelin were absent in the spinal cord of intact control animals. The expression levels did not differ in the UCB-MCs+AdV-GDNF, UCBMCs+AdV-EGFP and AdV-GDNF groups. However, in the AdVGDNF group, we observed numerous large axons displaying disruption of the ordered membrane structure, and in the AdV-EGFP group, we detected small clusters of axonal profiles exhibiting a $\mathrm{P}^{+}$myelin sheath without visible signs of degeneration. Our results showed that after SCI, cell-mediated and direct adenoviral vector-mediated delivery of the GDNF gene promoted Schwann cells migration into the spinal cord and significantly increased the number of axons featuring peripheral myelin.

In vivo expression analysis of recombinant GDNF and EGFP genes qRT-PCR: GDNF and EGFP mRNA expression was quantified by normalizing gene expression data against the levels of $18 \mathrm{~S}$ ribosomal RNA expression in the corresponding samples. GDNF mRNA expression in the spinal cord of AdV-GDNF-treated rats after 7, 14 and 30 postoperative days was 1200, 29500 and 1953 times higher relative to that at the corresponding times in untreated rats subjected to SCI (Figure 8). EGFP mRNA expression in the spinal cord of AdVEGFP-treated rats on Days 7, 14 and 30 after SCI was 77 500, 265000 and 130500 times higher than that at these time points in untreated rats subjected to SCI. In accord with these results, the levels of GDNF and EGFP mRNAs on Day 14 after SCI were respectively $\sim 24$ and $\sim 3$ times higher than the levels on Day 7 after SCI. However, GDNF and EGFP mRNA levels on Day 30 after SCI were $\sim 15$ and $\sim 2$ times lower, respectively, than those on Day 14 after SCI.

\section{Western blot analysis}

We performed western blotting to confirm the expression of the target recombinant proteins in the spinal cord at 7 days after adenoviral vector injection into the spinal cord following laminectomy (sham with AdV-EGFP and sham with AdV-GDNF) and after SCI (SCI with AdV-EGFP and SCI with AdV-GDNF) (Figure 9). Our results showed that GDNF expression was increased during the first week in the rats of the sham with AdV-GDNF and SCI with AdV-GDNF groups as compared with endogenous GDNF expression levels, and that it was also higher than that in the rats of these groups: sham with AdVEGFP, SCI with AdV-EGFP, SCI without any treatment and intact control. Moreover, EGFP was also detected in western blots of samples obtained from the sham with AdV-EGFP and SCI with AdV-EGFP groups. In these assays, staining with mouse monoclonal Abs against $\beta$-actin demonstrated that comparable amounts of total protein were loaded in the gels.

\section{Assessment of locomotor activity}

We assessed locomotor recovery after injury by using the BBB rating scale. In the case of all animals, the BBB score was 21 pre-injury and the bilateral hindlimb paralysis score was 0 immediately after injury. Evaluation of recovery of voluntary movements in the UCB-MCs + AdV-EGFP group showed gradual partial recovery, from a score of 3 

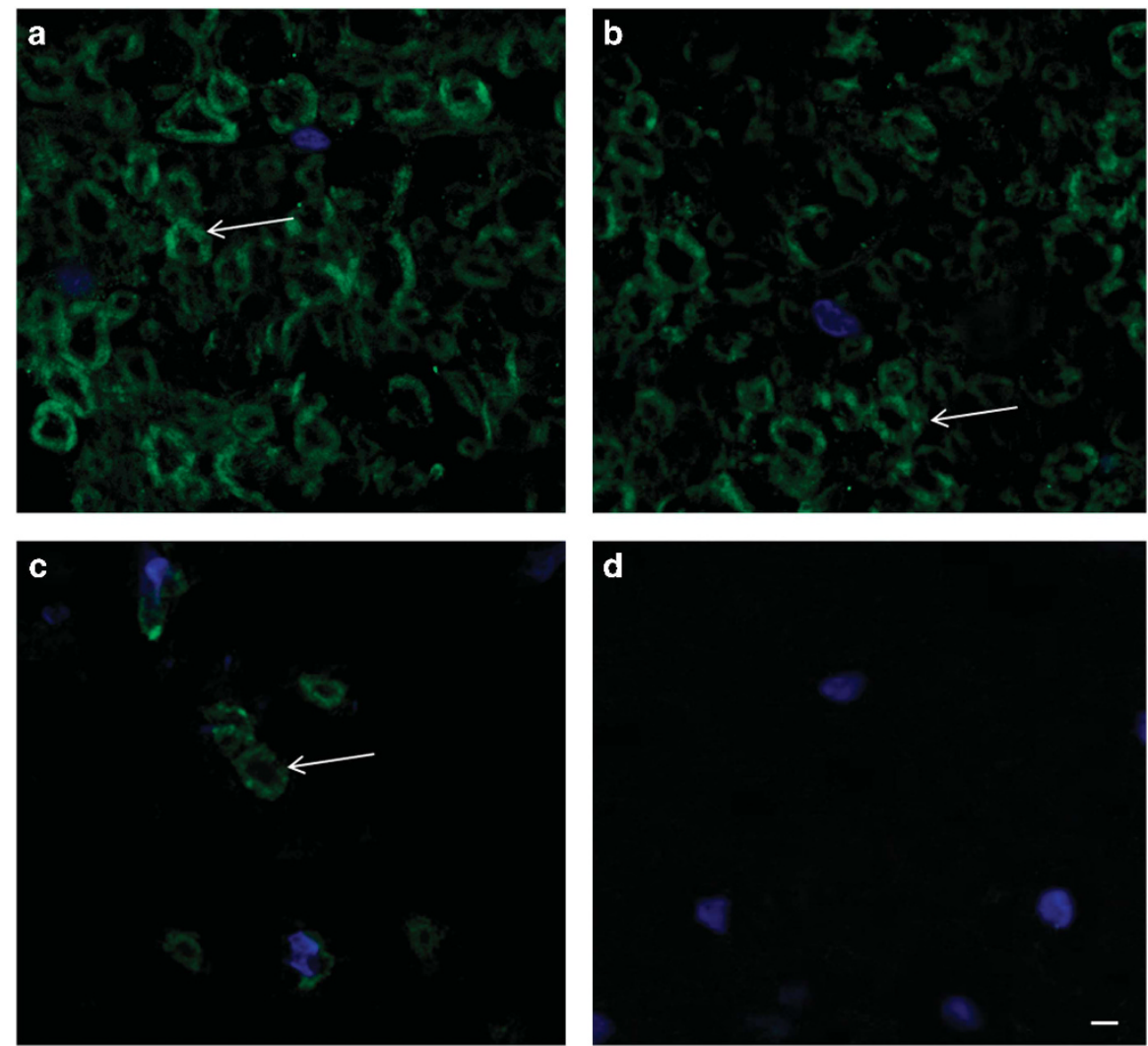

Figure 7 The figure panels show the labeling of cells with an Ab against PO (green) and with DAPI (blue) and provide evidence that PO ${ }^{+} \mathrm{Schwann}$ cells might form peripheral myelin (arrows) on Day 30 after SCl and delivery of UCB-MCs+AdV-GDNF (a), AdV-GDNF (b) and AdV-EGFP (c). PO+ Schwann cells were not detected in the intact control group (d). Differential changes in the expression of PO are shown at a distance of $5 \mathrm{~mm}$ from the SCl epicenter in the rostral direction. Scale bar: $5 \mu \mathrm{m}$.
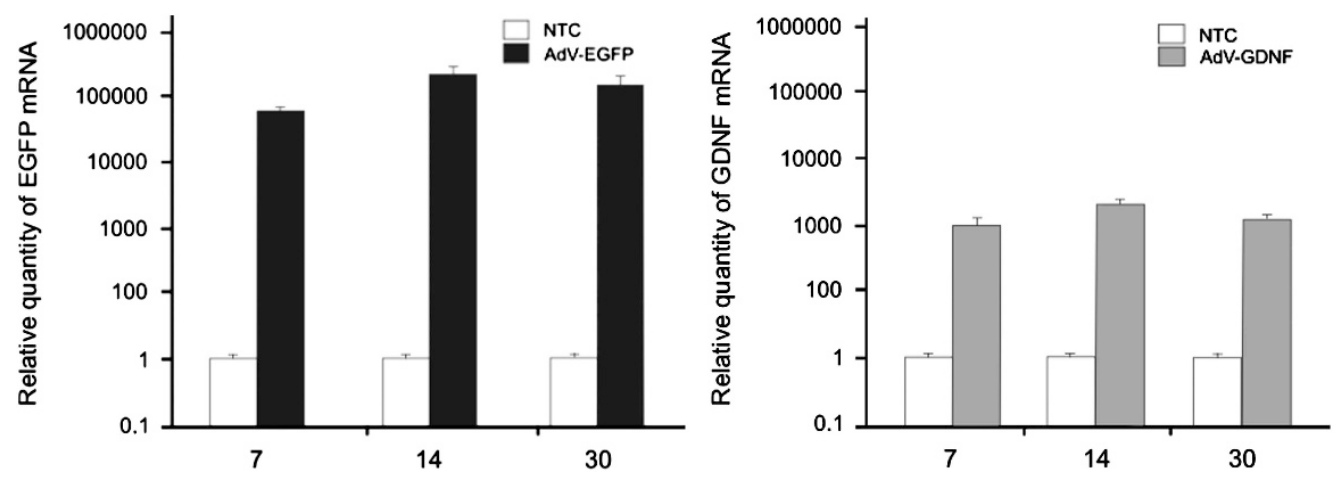

Figure 8 EGFP and GDNF mRNA expression on Days 7, 14 and 30 after SCI (nontransduced control, NTC) and after SCl followed by injection of AdV-EGFP or AdV-GDNF. The level of EGFP and GDNF mRNA expression in NTC was considered 100\%. Relative to the expression in NTC, EGFP mRNA expression in rat spinal cords simultaneously treated with SCI and AdV-EGFP was 77500, 265000 and 130500 times higher on Days 7, 14 and 30 after surgery, respectively, and GDNF mRNA expression on these days was 1200, 29500 and 1953 times higher, respectively. Statistically significant differences were detected between NTC and the experimental groups in all cases $(P<0.01)$.

by Day 7 after injury to a score of 11 by Day 29 (average recovery score $7.3 \pm 0.8$ ) (Figure 10a). By comparison, assessment of hindlimb function revealed enhanced locomotor function in the UCB-MCs + AdV-GDNF group; in this group, the BBB score reached 15 by Day 29 after injury (average recovery score $10.7 \pm 1.0$ ) (Figure 10a). The difference between the UCB-MCs+AdV-GDNF and UCB-MCs+AdVEGFP groups was significant $(P<0.05)$ on at least three post-injury days $(9,11$ and 13).
In the case of direct gene therapy, animals of the AdV-EGFP group showed an increase in the BBB score from 3 at Day 7 to 8 by Day 29 (average recovery score $6.8 \pm 0.5$ ), whereas the animals of the AdVGDNF group showed a substantial increase in the BBB score, from 9 at Day 7 to 17 by Day 29 (average recovery score $13.3 \pm 0.8$ ). The AdV-GDNF-treated rats showed significantly higher BBB scores than did AdV-EGFP controls at all examined time points starting from Day 7 following traumatic injury $(P<0.05)$ (Figure 10b). However, open- 
field behavioral scoring indicated that the BBB scores of the UCB-MCs + AdV-GDNF and AdV-GDNF groups did not differ in a statistically significant manner.

Thus, adenoviral vector-mediated GDNF gene transfer reversed functional deficiency in the locomotor system following acute SCI in rats. When UCB-MCs transduced with a recombinant adenoviral vector encoding GDNF were transplanted into the contused spinal cord, recovery of motor function was promoted. Within the first 29 days after the injury, the positive effect of cell-mediated gene delivery was more pronounced than that of direct gene injection; however, a statistically significant difference was not detected between the UCB-MCs+AdV-GDNF and AdV-GDNF groups.

\section{DISCUSSION}

In this study, we showed that both cell-mediated and direct GDNF gene delivery into the injured spinal cord improved motor function in rats. However, our measurement of the BBB score during the first month after SCI and immediate administration of the transgene did

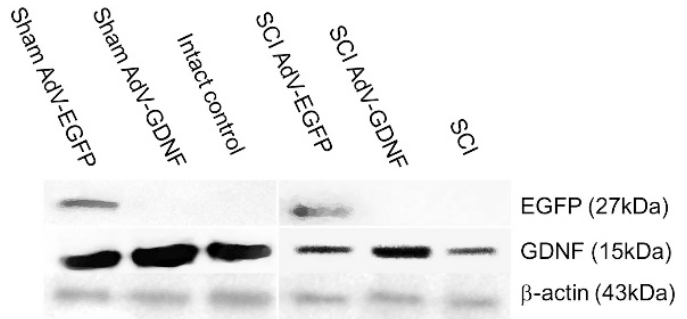

Figure 9 Western-blotting analysis of target recombinant proteins on the 7th day after injection of AdV-EGFP or AdV-GDNF into damaged and intact spinal cords. Staining with Abs against EGFP and GDNF revealed specific bands at 27 and $15 \mathrm{kDa}$ in tissue samples after administration of AdV-EGFP and AdV-GDNF, respectively. Signals were weaker after administration of AdV-EGFP and in samples that were not subjected to adenovirus-mediated gene transfer than in the AdV-GDNF. not reveal which of the two methods of GDNF gene delivery is more effective. To answer this question, the experimental animals will have to be observed for a period longer than 1 month.

We determined that the number of spared myelinated fibers increased as the distance from the injury epicenter increased. Compared with direct gene injection, cell-mediated GDNF gene delivery led to considerably more pronounced preservation of myelinated fibers in the remote segments of the spinal cord (5 vs $3 \mathrm{~mm}$ from the epicenter), and this might depend on the expansion of the therapeutic influence in cell-mediated therapy over long distances as a result of the migration of the transplanted cells. UCB-MCs are suitable for cell therapy because they can potentially differentiate into not only blood cells, but also other types of cells such as myoblasts of heart and skeletal muscle tissues, hepatocytes, vascular endothelial cells, neurons, oligodendrocytes and astrocytes. ${ }^{25}$ Previously, we showed that intravenously transplanted human UCB-MCs successfully homed in on the gray and white matter of the G93A ALS mouse spinal cord, survived there for a long period without immunosuppression, and differentiated into various cell types. ${ }^{19,20}$ Native human UCB-MCs can differentiate into endothelial and microglial cells and UCB-MCs transfected with plasmid vectors that concurrently expressed VEGF and NCAM-L1 showed considerable potential to differentiate into endothelial cells; moreover, UCB-MCs overexpressing VEGF and FGF2 transformed into astrocyte-like $\mathrm{S}_{100}{ }^{+}$cells and Oct4-Sox2 transfected UCB-MCs expressed the neuronal marker PGP9.5. ${ }^{26}$

Studies conducted using various approaches to deliver the GDNF gene have increasingly focused on examining the functional deficits and the preservation of the gray matter of the spinal cord, but these studies have primarily examined the survival of neurons ${ }^{10,13,27,28}$ and have mostly ignored the changes in glial cells. Therefore, in this study, we paid particular attention to the effects of direct and cell-mediated delivery of the GDNF gene on the phenotypic and quantitative characteristics of glial cells in the injured spinal cord. Our results indicated that direct and cell-mediated GDNF gene delivery into the site of SCI exerted distinct effects on the post-injury changes in the
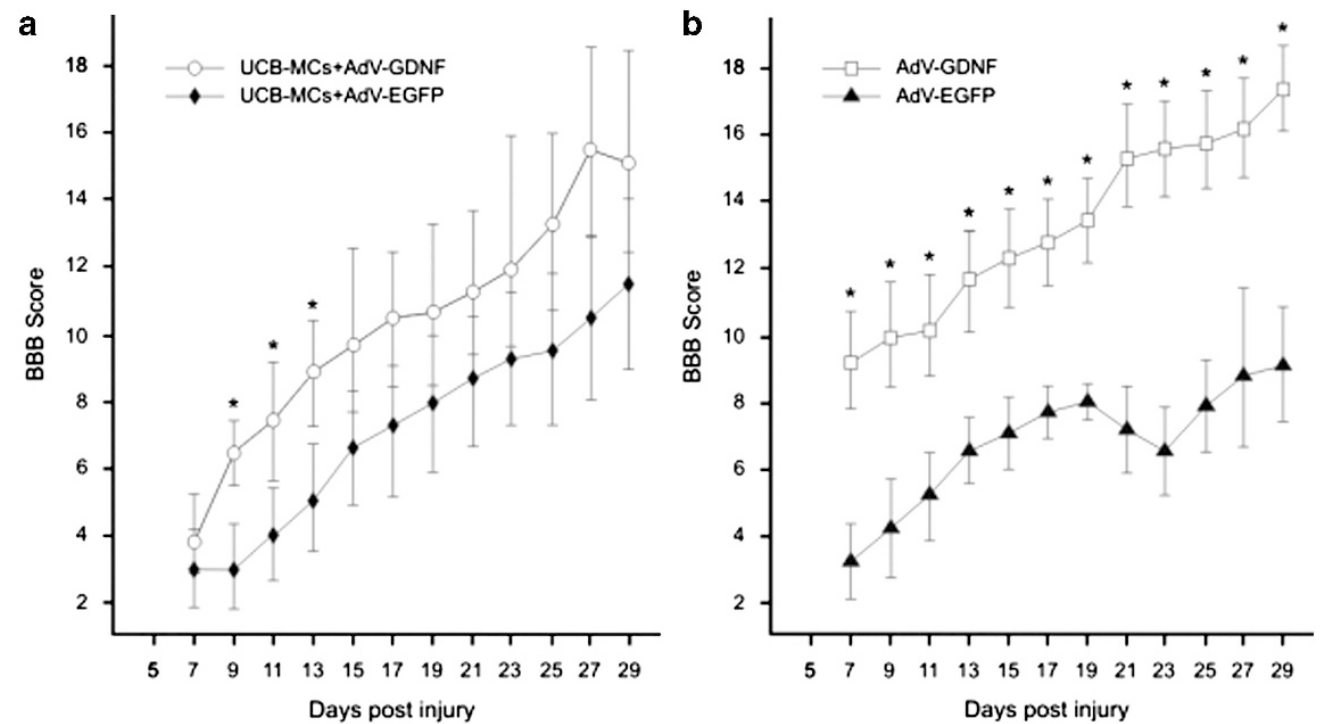

Figure 10 BBB locomotor scores post SCl obtained for the UCB-MCs+AdV-GDNF, UCB-MCs+AdV-EGFP, AdV-GDNF and AdV-EGFP groups. BBB scores were higher in the UCB-MCs+AdV-GDNF (a, circle) and AdV-GDNF ( $\mathbf{b}$, square) groups than in the UCB-MCs+AdV-EGFP (a, rhombus) and AdV-EGFP (b, triangle) groups, respectively $\left({ }^{*} P<0.05\right)$. However, the BBB score did not differ significantly between the UCB-MCs+AdV-GDNF (a, circle) and AdV-GDNF (b, square) groups. The values are expressed as means \pm s.e.m. 
populations of glial cells and the expression of the phenotypic markers of astrocytes and oligodendrocytes.

Direct gene therapy (AdV-GDNF) did not affect GFAP expression in any of the examined zones, but it increased the expression of S100B in the DREZ and that of AQP4 in the VF at a distance of $10 \mathrm{~mm}$ from the SCI epicenter. Because the expression of GFAP, the main marker of the astrocyte cytoskeleton, reflects the severity of astrogliosis and glial-scar presence, an absence of a direct influence of gene therapy on GFAP expression in our experiments can be interpreted as a positive effect. In the DREZ, S100B expression might have been increased because of the migration of endogenous $\mathrm{S}_{100 \mathrm{~B}^{+}}$Schwann cells from the dorsal roots to the injury area (see below). Moreover, delivery of the GDNF gene increased the expression of AQP4 in the VF, but not in areas containing gray matter (DREZ, VH); this can indirectly indicate that the white matter harbors astrocytes that possess specific phenotypic characteristics that differ from those of these cells in the gray matter. Both UCB-MC-mediated and direct delivery of the GDNF gene increased the expression of AQP4 in the same area, the VF, and this confirmed a specific effect of GDNF on a population of astrocytes in the white matter. GDNF-dependent maintenance of $\mathrm{AQP}^{+}$astrocytes and increased expression of the AQP4 water channel might provide a milieu that is highly conducive to the survival of endogenous and transplanted cells in the injured rat spinal cord. These results indicate that cell-mediated GDNF gene delivery largely contributes to maintaining a population of astrocytes and activating GFAP and $\mathrm{S} 100 \mathrm{~B}$ expression.

The gap junction protein $\mathrm{Cx} 47$ is expressed mainly in oligodendrocytes in highly myelinated CNS tissues and in a few cells that express the calcium-binding protein $\mathrm{S} 100 \mathrm{~B}$ subunit. ${ }^{24} \mathrm{Cx} 47$ is crucial for myelination and oligodendrocyte function. ${ }^{29}$ Odermatt et al. ${ }^{24}$ investigated the optic nerve and other CNS tissues in Cx47-deficient mice and demonstrated abnormal myelin vacuolation of nerve fibers at the site where axons are first contacted by oligodendrocytes and myelination starts. Direct gene therapy (AdV-GDNF) supported a $\mathrm{Cx}_{4} 7^{+}$cell population in the DREZ at a distance of $5 \mathrm{~mm}$ from epicenter and in the DREZ, VH and VF at a distance of $10 \mathrm{~mm}$ from epicenter, and the strongest effect was observed in the VH. This potentially indicates that the effect of administering a recombinant adenovirus carrying a therapeutic gene can be detected at a considerable distance from the point of injection. In the case of the number of $\mathrm{Cx} 47^{+}$cells, the advantage of cell-mediated therapy over direct gene therapy was evident in the $\mathrm{VH}$ at a distance of $5 \mathrm{~mm}$ from the injury epicenter. However, in the DREZ, at a distance of $10 \mathrm{~mm}$ from epicenter in the rostral direction, $\mathrm{Cx} 47^{+}$cells were more actively supported by direct gene therapy than by UCB-MC-mediated gene delivery. Why the effect of direct AdV-GDNF injection was stronger than that of cell-mediated gene delivery remains unclear.

Schwann cells migrate to damaged areas of the spinal cord and participate in remyelination at those sites, and these cells are considered to be a source of multiple molecular signals that potentially support the growth of axons in the CNS. A previous study reported that after the formation of a substitutive peripheral myelin, Schwann cells are gradually replaced by oligodendrocytes. ${ }^{30}$ We previously showed that UCB-MC-mediated delivery of VEGF and FGF2 genes stimulated the survival and migration of endogenous Schwann cells within the injured rat spinal cord. ${ }^{31}$ The results of this study indicate that GDNF appears to exert a similar effect. GDNF has been shown to stimulate the migration of Schwann cells and to enhance myelination through NCAM signaling pathways that regulate myelin formation. ${ }^{32}$ GDNF expression was previously reported to promote the differentiation of Schwann cells back to their native phenotypes by stimulating the receptor GFR $\alpha 1$, increase the expression of phenotype-specific markers, ${ }^{33}$ and induce Schwann cell migration to the lesion site, and thus lead to the remyelination of axons. ${ }^{14}$ Although GDNF did not affect the proliferation of isolated Schwann cells, it enhanced the proliferation of Schwann cells that were already in contact with axons. ${ }^{34}$ In this study, the results of RT-PCR and western-blotting analyses confirmed that the expression of exogenous GFP and GDNF was markedly upregulated in the experimental groups. It follows that cell-mediated and direct GDNF delivery induced the increase in Schwann cells within the injured rat spinal cord.

The neurotrophic action of GDNF on spinal motor neurons is widely recognized, ${ }^{6}$ and the effectiveness of GDNF in SCI treatment has been extensively investigated. ${ }^{4,5}$ In this study, we have documented that greater functional recovery was obtained using UCB-MCmediated gene therapy than using direct gene delivery, an effect that clearly depends on UCB-MCs. The contribution of UCB-MCs to neuroregeneration might be explained by these findings: (1) ex vivo transduction of UCB-MCs with the Ad-GDNF vector leads to effective expression of GDNF; (2) UCB-MCs secrete different neuroprotective factors besides GDNF; 35,36 and (3) UCB-MCs differentiate into endothelial and microglial cells. ${ }^{20}$ The functional recovery reflects the process of neuroregeneration, which proceeds through (1) tissue sparing, (2) reversed degeneration of myelinated fibers and (3) redistribution of the astrocytes, oligodendrocytes and Schwann cells that are stimulated by recombinant GDNF and human UCB-MCs. However, uncovering the molecular mechanisms of various inter- and intra-cellular cascades involved was beyond the scope of this study; our main goal here was to evaluate the effectiveness of cell-mediated and direct gene therapy of SCI by using an adenoviral vector carrying the GDNF gene.

\section{CONCLUSIONS}

Transplantation of UCB-MCs is a promising strategy for enhancing posttraumatic spinal cord regeneration. Delivery of the GDNF gene into the site of injury holds considerable potential as a therapeutic intervention in SCI. The use of adenoviruses serves as an efficient method of delivering a transgene and thereby enables the expression of the exogenous gene for long periods.

\section{DATA ARCHIVING}

There were no data to deposit.

\section{CONFLICT OF INTEREST}

The authors declare no conflict of interest.

\section{ACKNOWLEDGEMENTS}

We thank TV Povysheva (Kazan State Medical University, Kazan, Russia) for assistance in some of the experiments. This work was supported by grants from RFBR - Russia (14-04-31 246), OPTEC (33/2014/51-Kzn), and a Presidential grant for government support of young Russian scientists $(\mathrm{PhD})$ from the Russian Federation (4020.2015.7). This work was also funded in part by the Russian Ministry of Science and Education (Agreement No. 02.A03.21.0002) to support the Program of Competitive Growth of Kazan Federal University. The research was performed using the equipment of the Interdisciplinary Center for Collective Use of Kazan Federal University, supported by Ministry of Education of Russia (ID RFMEFI59414X0003).

1 Airaksinen MS, Saarma M. The GDNF family: signalling, biological functions and therapeutic value. Nat Rev Neurosci 2002; 3: 383-394. 
2 Tansey MG, Baloh RH, Milbrandt J, Johnson EM Jr. GFRalpha-mediated localization of RET to lipid rafts is required for effective downstream signaling, differentiation, and neuronal survival. Neuron 2000; 25: 611-623.

3 Encinas M, Tansey MG, Tsui-Pierchala BA, Comella JX, Milbrandt J, Johnson EM Jr. c-Src is required for glial cell line-derived neurotrophic factor (GDNF) family ligandmediated neuronal survival via a phosphatidylinositol-3 kinase (PI-3 K)-dependent pathway. J Neurosci 2001; 21: 1464-1472.

4 Cheng H, Wu JP, Tzeng SF. Neuroprotection of glial cell line-derived neurotrophic factor in damaged spinal cords following contusive injury. J Neurosci Res 2002; 69: 397-405.

5 Iannotti C, Li H, Yan P, Lu X, Wirthlin L, Xu XM. Glial cell line-derived neurotrophic factor-enriched bridging transplants promote propriospinal axonal regeneration and enhance myelination after spinal cord injury. Exp Neurol 2003; 183: 379-393.

6 Barati S, Hurtado PR, Zhang SH, Tinsley R, Ferguson IA, Rush RA. GDNF gene delivery via the p75(NTR) receptor rescues injured motor neurons. Exp Neurol 2006; 202: 179-188.

7 Mills CD, Allchorne AJ, Griffin RS, Woolf CJ, Costigan M. GDNF selectively promotes regeneration of injury-primed sensory neurons in the lesioned spinal cord. $\mathrm{Mol} \mathrm{Cell}$ Neurosci 2007; 36: 185-194.

8 Storer PD, Dolbeare D, Houle JD. Treatment of chronically injured spinal cord with neurotrophic factors stimulates betall-tubulin and GAP-43 expression in rubrospinal tract neurons. J Neurosci Res 2003; 74: 502-511.

9 Lu KW, Chen ZY, Jin DD, Hou TS, Cao L, Fu Q. Cationic liposome-mediated GDNF gene transfer after spinal cord injury. J Neurotrauma 2002; 19: 1081-1090.

10 Sakurai M, Abe K, Hayashi T, Setoguchi Y, Yaginuma G, Meguro T et al. Adenovirus mediated glial cell line-derived neurotrophic factor gene delivery reduces motor neuron injury after transient spinal cord ischemia in rabbits. J Thorac Cardiovasc Surg 2000, 120: 1148-1157.

11 Koelsch A, Feng Y, Fink DJ, Mata M. Transgene-mediated GDNF expression enhances synaptic connectivity and GABA transmission to improve functional outcome after spinal cord contusion. J Neurochem 2010; 113: 143-152.

12 Tai $\mathrm{MH}$, Cheng H, Wu JP, Liu YL, Lin PR, Kuo JS et al. Gene transfer of glial cell linederived neurotrophic factor promotes functional recovery following spinal cord contusion. Exp Neurol 2003; 183: 508-515.

13 Tang XQ, Wang Y, Huang ZH, Han JS, Wan Y. Adenovirus-mediated delivery of GDNF ameliorates corticospinal neuronal atrophy and motor function deficits in rats with spinal cord injury. Neuroreport 2004; 15: 425-429.

14 Blesch A, Tuszynski MH. Cellular GDNF delivery promotes growth of motor and dorsal column sensory axons after partial and complete spinal cord transections and induces remyelination. J Comp Neurol 2003; 467: 403-417.

15 Yan HB, Zhang ZM, Jin DD, Wang XJ, Lu KW. The repair of acute spinal cord injury in rats by olfactory ensheathing cells graft modified by glia cell line-derived neurotrophic factor gene in combination with the injection of monoclonal antibody IN-1. Zhonghua Wai Ke Za Zhi 2009; 47: 1817-1820.

16 Deng XY, Zhou RP, Lu KW, Jin DD. Lithium chloride combined with human umbilical cord blood mesenchymal stem cell transplantation for treatment of spinal cord injury in rats. Nan Fang Yi Ke Da Xue Xue Bao 2010; 30: 2436-2439.

17 Park DH, Lee JH, Borlongan CV, Sanberg PR, Chung YG, Cho TH. Transplantation of umbilical cord blood stem cells for treating spinal cord injury. Stem Cell Rev 2011; 7: 181-194.

18 Han ZX, Shi Q, Wang DK, Li D, Lyu M. Basic biological characteristics of mesenchymal stem cells derived from bone marrow and human umbilical cord. Zhongguo Shi Yan Xue Ye Xue Za Zhi 2013; 21: 1248-1255.

19 Rizvanov AA, Kiyasov AP, Gaziziov IM, Yilmaz TS, Kaligin MS, Andreeva DI et al. Human umbilical cord blood cells transfected with VEGF and L(1)CAM do not differentiate into neurons but transform into vascular endothelial cells and secrete neuro-trophic factors to support neurogenesisa novel approach in stem cell therapy. Neurochem Int 2008; 53: 389-394.
20 Rizvanov AA, Guseva DS, Salafutdinov II, Kudryashova NV, Bashirov FV, Kiyasov AP et al. Genetically modified human umbilical cord blood cells expressing vascular endothelial growth factor and fibroblast growth factor 2 differentiate into glial cells after transplantation into amyotrophic lateral sclerosis transgenic mice. Exp Biol Med (Maywood) 2011; 236: 91-98.

21 Islamov RR, Rizvanov AA, Mukhamedyarov MA, Salafutdinov II, Garanina EE, Fedotova VY et al. Symptomatic improvement, increased life-span and sustained cell homing in amyotrophic lateral sclerosis after transplantation of human umbilical cord blood cells genetically modified with adeno-viral vectors expressing a neuroprotective factor and a neural cell adhesion molecule. Curr Gene Ther 2015; 15 266-276.

22 Lebedev SV, Timofeyev SV, Zharkov AV, Schipilov VG, Chelyshev JA, Masgutova GA et al. Exercise tests and BBB method for evaluation of motor disorders in rats after contusion spinal injury. Bull Exp Biol Med 2008; 146: 489-494.

23 Watzlawik JO, Warrington AE, Rodriguez M. PDGF is required for remyelinationpromoting IgM stimulation of oligodendrocyte progenitor cell proliferation. PLoS One 2013; 8: e55149.

24 Odermatt B, Wellershaus K, Wallraff A, Seifert G, Degen J, Euwens C et al. Connexin 47 (Cx47)-deficient mice with enhanced green fluorescent protein reporter gene reveal predominant oligodendrocytic expression of $\mathrm{C} \times 47$ and display vacuolized myelin in the CNS. J Neurosci 2003; 23: 4549-4559.

25 Korbling M, Robinson S, Estrov Z, Champlin R, Shpall E. Umbilical cord blood-derived cells for tissue repair. Cytotherapy 2005; 7: 258-261.

26 Guseva D, Rizvanov AA, Salafutdinov II, Kudryashova NV, Palotás A, Islamov RR. Overexpression of Oct4 and Sox2 transcription factors enhances differentiation of human umbilical cord blood cells in vivo. Biochem Biophys Res Commun 2014; 451: 503-509.

27 Liu G, Wang X, Shao G, Liu Q. Genetically modified Schwann cells producing glial cell line-derived neurotrophic factor inhibit neuronal apoptosis in rat spinal cord injury. $\mathrm{Mol}$ Med Rep 2014; 9: 1305-1312.

28 Lu KW, Chen ZY, Hou TS. Protective effect of liposome-mediated glial cell line-derived neurotrophic factor gene transfer in vivo on motoneurons following spinal cord injury in rats. Chin J Traumatol 2004; 7: 275-279.

29 Scherer SS, Chance PF. Myelin genes: getting the dosage right. Nat Genet 1995; 11: 226-228.

30 Jasmin L, Janni G, Moallem TM, Lappi DA, Ohara PT. Schwann cells are removed from the spinal cord after effecting recovery from paraplegia. J Neurosci 2000; 20: 9215-9223.

31 Mukhamedshina YO, Shaymardanova GF, Muhitov AR, Salafutdinov II, Rizvanov AA, Zarubina VN et al. Survival and differentiation of endogenous Schwann cells migrating into spinal cord under the influence of neurotrophic factors. Cell Transplant Tissue Eng 2012; 7: 125-129.

32 Iwase T, Jung CG, Bae H, Zhang M, Soliven B. Glial cell line-derived neurotrophic factor-induced signaling in Schwann cells. J Neurochem 2005; 94: 1488-1499.

33 Jesuraj NJ, Marquardt LM, Kwasa JA, Sakiyama-Elbert SE. Glial cell line-derived neurotrophic factor promotes increased phenotypic marker expression in femoral sensory and motor-derived Schwann cell cultures. Exp Neurol 2014; 257: 10-18.

34 Zhang L, Ma Z, Smith GM, Wen X, Pressman Y, Wood PM et al. GDNF-enhanced axonal regeneration and myelination following spinal cord injury is mediated by primary effects on neurons. Glia 2009; 57: 1178-1191.

35 Suen Y, Lee SM, Schreurs J, Knoppel E, Cairo MS. Decreased macrophage colonystimulating factor mRNA expression from activated cord versus adult mononuclear cells: altered post-transcriptional stability. Blood 1994; 84: 4269-4277.

36 Taguchi A, Soma T, Tanaka H, Kanda T, Nishimura H, Yoshikawa $\mathrm{H}$ et al. Administration of CD34+ cells after stroke enhances neurogenesis via angiogenesis in a mouse model. J Clin Invest 2004; 114: 330-338. 